Article

\title{
Implementing Agricultural Pruning to Energy in Europe: Technical, Economic and Implementation Potentials
}

\author{
Arkadiusz Dyjakon ${ }^{1, *(1)}$ and Daniel García-Galindo ${ }^{2}$ \\ 1 Institute of Agricultural Engineering, Wroclaw University of Environmental and Life Sciences, \\ 51-630 Wroclaw, Poland \\ 2 Research Centre for Energy Resources and Consumption (CIRCE), 50018 Zaragoza, Spain; \\ daniel.garcia@fcirce.es \\ * Correspondence: arkadiusz.dyjakon@upwr.edu.pl; Tel.: +48-71-320-5945
}

Received: 24 March 2019; Accepted: 17 April 2019; Published: 22 April 2019

\begin{abstract}
The use of new sources of biomass residues for energy purposes in Europe is crucial for increasing the share of renewable energy sources and the limitation of carbon dioxide emissions. The residues coming from regular pruning of permanent crops are an alternative to conventional fuels. The paper is focused on the assessment of European pruning potentials in European Union (EU28) in line with the nomenclature of territorial units (NUTs) at NUTs0, NUTs2 and NUTs3 level. The assessment indicates that the yearly theoretical and technical potential of that biomass is 13.67 MtDM (or 252.0 PJ. $\mathrm{yr}^{-1}$ ) and 12.51 MtDM (or 230.6 PJ. $\mathrm{yr}^{-1}$ ), respectively. The economic potential has been assessed based on different management or exploitation models: management of pruning as a waste, self-consumption, and demand-driven mobilisation by consumption centres at small, medium and large scales. The utilisation of pruning when gathering is compulsory coincides with the technical potential. Under self-consumption, up to $10.98 \mathrm{MtDM}$ per year could be effectively mobilised (202.3 PJ. $\left.\mathrm{yr}^{-1}\right)$. The creation of new value chains for delivery of pruning biomass ranges 7.30 to 8.69 MtDM per year (from 134.5 to $160.2 \mathrm{PJ} \cdot \mathrm{yr}^{-1}$ ). When applying further constraints related to other existing uses the implementation of the potential further descends, ranging from 6.18 to $10.66 \mathrm{MtDM}$ per year (from 113.9 to $196.4 \mathrm{PJ} \cdot \mathrm{yr}^{-1}$ ). The analysis shows that the amount of available pruning residues is regionally scattered; however, most of them (ca. 80\%) are located in the Mediterranean area.
\end{abstract}

Keywords: permanent crop; pruning; olive; fruit; nuts; vineyard; biomass potential; EU28

\section{Introduction}

The increase of renewable energy sources in energy production is one of the key issues to reduce $\mathrm{CO}_{2}$ emissions as well as the utilisation of fossil fuels. This is one of the key points of the European Commission's communication entitled 'Energy roadmap 2050' (COM(2011) 885 final [1]. With the aim of increasing the share of renewable energies, Europe (EU28) is developing ambitious strategies-like the 2030 Framework for climate and energy [2] published in 2014-and policy instruments such as the Directive (EU) 2018/2001 on the promotion of the use of energy from renewable sources [3]. The objectives of the 2030 Framework for climate and energy were revised upwards in 2018, setting a target for renewable energies in the share of the energy consumption of $32 \%$. Bioenergy represents currently more than $60 \%$ of the renewable energy consumed in the EU28 [4]. With respect to the total primary energy, biomass resources contribute to $5631 \mathrm{PJ}$ in the primary energy mix, representing a share of $18 \%$. By 2030 it is projected that the participation of bioenergy will be $50 \%$ in the final energy of renewable sources with a contribution of circa $6200 \mathrm{PJ}$ (equivalent to mobilization of $450 \mathrm{MtDM}$ per year) [5]. To 
date, forest biomass is the main source for bioenergy production. Agricultural biomass, however, may play a major role as bioenergy expands in future, thus becoming strategic in reaching the renewable energy targets by 2030 and 2050 in EU28.

Biomass coming from agricultural activities (agroresidues and energy crops, also referred to as agrobiomass) is recognized to have a significant energy potential [6-9] Moreover, when produced endogenously, biomass is considered as a local and sustainable energy resource with a low footprint for the environment [3].

Agricultural biomass, as a waste product, can be gathered from different sources, including pruning of permanent crops-olive groves, fruit plantations and vineyards. Unfortunately, there is currently a lack of more detailed studies on agricultural pruning productivity at the European level. Furthermore, at the European scale, the pruning residues as a potential resource are very often disregarded, or their assessment was performed in more simplified form in comparison to other biomass resources like forestry biomass, straw, agro-industrial residues or energy crops [7-16]. In the European National Renewable Action Plans (NREAPs) published in 2010 by the 28 European member states, only in two cases (Spain and France) specific details on the potential and strategic relevance of these agricultural residues were included. In contrast, straw was quantified in 14 NREAPs, and agro-residues (as a whole) and energy crop potentials were reported in more than 20 NREAPs.

Notwithstanding the absence of explicit results for pruning potentials in the aforementioned research works, European pruning biomass potentials have been the object of assessments recently in the framework of two European research projects: Biomass Futures [15] and S2Biom [17]. The works carried out in both projects intended to provide biomass assessments (in relation to the Nomenclature of Territorial Units - NUTs) and strategic analysis to support policy makers in preparing their policies on biomass supply. The aforementioned studies assessed the total (in fact theoretical) biomass potentials by multiplying in each territorial unit (NUTs2 and NUTs3) the hectares-output of the land use scenarios by 2020 and 2030 - of land dedicated to each group of crops by the corresponding biomass yield $\left(\mathrm{t} \cdot \mathrm{ha}^{-1}\right)$. The efforts and accuracy placed to obtain land projections are in contrast with the limited certainty of the pruning productivity ratios: using a constant productivity ratio-residue to surface ratios (RSR) - by crop species in the whole of Europe [15] or by country [17].

A recent research work prepared by García-Galindo et al. [18] included a new methodology scoped to obtain pruning biomass yields (denoted as RSR), and expressed in tons per hectare of dry matter ( $\mathrm{tDM} \cdot \mathrm{ha}^{-1}$ ) that can be obtained in the annual pruning operations-tailored to each European geographical unit (NUTs2 and NUTs3). The values of RSR by NUTs unit was the result of statistical correlation analysis between the RSR values and several climatic, agro-climatic and agro-ecological indicators. This can be considered an improvement in the assessments of pruning biomass potentials in studies carried out at large scale, thus improving its certainty, a need that was already pointed out by Panoutsou et al. [19]. However, these ratios are multiplied by the land surface utilised to grow a crop lead to an estimation of the total (theoretical) potential, only.

Theoretical potentials are the overall maximum potentials that can be produced in an area. However, the practical exploitation of the potentials shall be the subject of multiple constraints of a diverse nature: technical, economic, market related, social, environmental or linked to sustainability requirements. In order to harmonise the diverse types of assessments and potentials, the next classification is agreed upon by multiple researchers in order to develop and arrange biomass assessments and [19-21]:

- Theoretical potential (TH): the overall maximum amount of terrestrial biomass which can be considered theoretically available for bioenergy production within fundamental bio-physical limits.

- Technical potential (T): fraction of the theoretical potential which is available when considering current technological possibilities (such as harvesting techniques, infrastructure and accessibility, processing techniques).

- Economic potential (E): the share of the technical potential which meets criteria of economic profitability. 
- Implementation potential (I): fraction of the economic potential that can be implemented within a certain time frame (existing socio-economic constraints may limit the economically affordable biomass).

- Sustainable implementation potential (S): the result of integrating environmental, economic and social sustainability criteria in biomass resource. The share of the implementation potential not considered as sustainable, is subtracted.

In respect to pruning biomass assessments there are multiple works that have considered pruning biomass in local, regional, and national scales. However, pruning is usually not an object of sufficient insight, and there is scarce information on the technical, economic, implementation and sustainable potentials. Currently, the Biomass Futures [15] and S2Biom [17] projects are unique studies providing for Europe the whole set of potentials for pruning disaggregated by NUTs units and crop groups. The latter research project estimated the theoretical potentials based on the projected land cultivated with olive, vineyards and fruit trees by 2020 or 2030 . The area was multiplied by regional pruning biomass productivity. The theoretical potential was transformed into technical potential by assuming a maximum amount of collectable biomass per hectare and by applying a constant rate of efficiency in collecting pruning biomass. Biomass road-side costs were obtained following activity-based costing methodologies (agricultural residues costs at field side included the harvesting and at-field treatments). Results of road-side costs for pruning residues were rather high ranging $€ 100-150 \mathrm{t}^{-1}$ of dry matter $\left(€ \cdot \mathrm{tDM}^{-1}\right)$ for most of the European regions (meaning road-side costs above $€ 65-97.5 \mathrm{t}^{-1}$ of biomass at $35 \%$ moisture) [22]. When compared to the actual existing value chains, it is reported that plant-gate market prices for shredded agricultural pruning wood from $€ 45$ to $€ 70 \mathrm{t}^{-1}$ (biomass as received), and from $€ 37$ to $€ 73 \mathrm{t}^{-1}$ when it is commercialised as bales [23]. Authors argued the high costs were caused by the effect of parcel sizes, but concluded the model utilised was able to capture the fact that gathering pruning biomass involves a relevant cost.

Beyond the pruning economic potentials, the main factor evaluated for assessing the implementation potentials in previous works is typically the competitiveness of the expected expansion of pruning use for other purposes [17]. The complementary part is considered as available potential for expanding more uses. Sustainable potentials can be obtained by applying models considering the soil carbon balance, and the amount of biomass to be left on agricultural soils to maintain the soil organic carbon (SOC) in the long term [22,24].

The present work aims (i) to present a simple and replicable method for the estimation of the theoretical $(\mathrm{TH})$, technical $(\mathrm{T})$, economic $(\mathrm{E})$ and implementation (I) pruning biomass potentials in Europe; (ii) to facilitate the interpretation of the estimated potentials by policy makers and other users considering the use of pruned biomass for energy purposes; and (iii) to present the methods to assess the sustainable (S) potentials and to discuss how the consideration of sustainability could be implemented and limit the use of the agricultural pruning wood.

In this regard, the present work places special care in the potentials that can be relevant for designing supply strategies in Europe, principally technical, economic and implementation potentials. It arises from a practical point view as a technical potential is a first real estimation of exploitable biomass that might not be economically justified but is actually collected [25].

\section{Materials and Methods}

The object of the present article is the assessment of the selected biomass potential of the agricultural pruning biomass produced in pruning maintenance carried out with annual/biennial frequency. Other biomass production coming from diverse pruning operations is not considered, among them: green residues from fructification pruning and plant clearing (to reduce shading), wooden parts from very intense operations applied only after several years (restructuring pruning to reshape plant structure and size) or graft pruning (all branches are removed to leave the rootstock and to initiate the bud). The present work assesses the theoretical (TH), technical (T), economic (E) and implementation (I) potentials for agricultural prunings in EU28. 


\subsection{General Approach}

The estimation of the sustainable potentials is approached following the recommendations on biomass assessments harmonisation of the BEE [20] and CEUBIOM [21] projects. The first step is the assessment of the biomass theoretical potentials-denoted $\mathrm{Bio}_{\mathrm{TH}}$ - which considers the overall maximum amount of biomass theoretically attainable. The subsequent biomass potentials-technical, economic and implementation potential-are assessed through a cascade process where a set of coefficients of reduction $(\mathrm{CR})$ are applied. Sustainable potentials can be calculated as well by means of adequate CRs to be applied to the implementation potential, even though in the present work sustainable potentials are discussed, but not assessed numerically. The CRs reflect the impact of each constraint, and quantify the share of the upstream potential that has to be considered unavailable for the subsequent downstream potential type. The cascade process is presented in Figure 1.

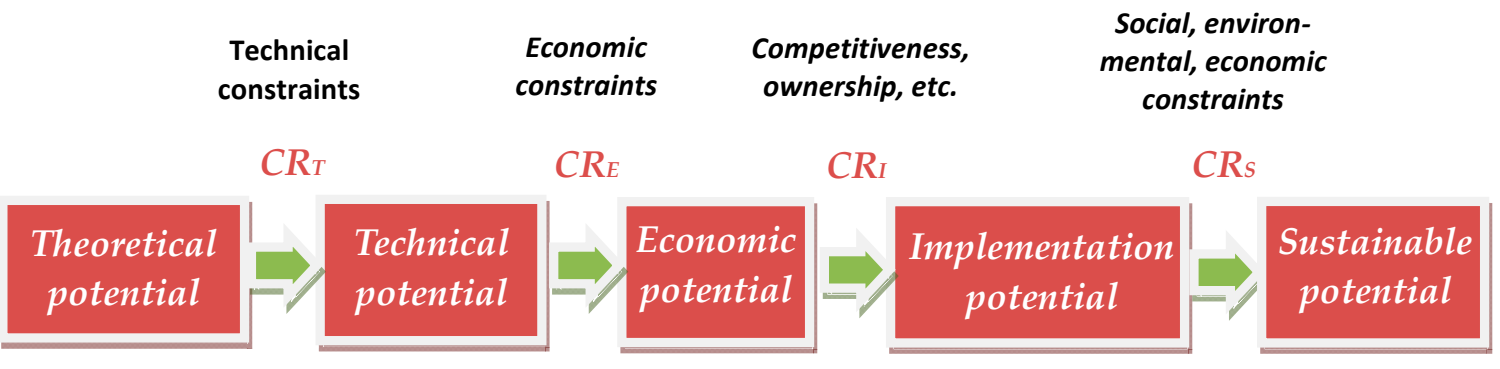

Figure 1. Flowchart and coefficients of reduction (CRs) for the assessment of pruning potentials.

Following this approach and the coefficients of reduction applied as multiplicative reducing terms, the implementation biomass potentials can be estimated according to Equation (1):

$$
B \mathrm{Bio}_{I}=B \mathrm{Bio}_{T H} \times\left(1-C R_{T}\right) \times\left(1-C R_{E}\right) \times\left(1-C R_{I}\right)
$$

Sustainable potentials can be calculated following the same approach, by applying the coefficient of reduction on sustainability to the values of implementation potentials as expressed in Equation (2):

$$
\operatorname{Bio}_{S}=B i_{I} \cdot\left(1-C R_{S}\right)
$$

Each CR class is composed of at least one limiting factor. The value of each composed multiplicative term is obtained as denoted in Equation (3):

$$
\left(1-C R_{X}\right)=\prod_{i=1}^{n}\left(1-C R_{X_{i}}\right)
$$

where $C R_{X}$ denotes a class $X$ which cases are $\mathrm{T}$ (Technical), $\mathrm{E}$ (Economic) and I (Implementation), where $C R_{X i}$ are the subclasses included into the Coefficient of Reduction $X$ to consider the diverse constraints limiting the use of the biomass resources. The CRs applied in the present work, and its subclasses are summarised in Table 1. The methodology followed for implementing each coefficient of reduction is presented subsequently in the next methodology sections. 
Table 1. Description of the coefficients of reduction and its subclasses.

\begin{tabular}{|c|c|c|}
\hline Constraint & $C R_{X i}$ & Description \\
\hline \multirow[t]{2}{*}{ Technical } & $C R_{T_{-} L O S S}$ & $\begin{array}{l}\text { Losses during pruning collection: part of the pruning wood not } \\
\text { collected due to technical limitations of the collecting system. }\end{array}$ \\
\hline & $C R_{T \_S L O P E}$ & $\begin{array}{c}\text { Slope: part of the fields that are on steep slopes that may constrain } \\
\text { pruning harvest. }\end{array}$ \\
\hline \multirow{5}{*}{ Economic scenarios } & $C R_{E_{-} \text {WASTE }}$ & $\begin{array}{l}\text { No economic limitation (a whole technical potential is economical). } \\
\text { The scenario of a total obligation for pruning removal from fields, or } \\
\text { where pruning is targeted by waste management programs. }\end{array}$ \\
\hline & $C R_{E \_S E L F}$ & $\begin{array}{l}\text { Self-consumption scenario: a minimum land tenure is considered } \\
\text { necessary for triggering self-consumption. }\end{array}$ \\
\hline & $C R_{E_{-} C O M-S}$ & $\begin{array}{c}\text { Commercial at small scale: representing local value chains where a } \\
\text { local service company is able to establish a new activity to collect } \\
\text { the pruning wood locally. }\end{array}$ \\
\hline & $C R_{E_{-} C O M-M}$ & $\begin{array}{l}\text { Commercial at medium scale: representing local value chains where } \\
\text { a local service company or a final consumer organises the collection } \\
\text { of pruning biomass for a medium-size application. }\end{array}$ \\
\hline & $C R_{E_{-} C O M-L}$ & $\begin{array}{c}\text { Commercial at large scale: pruning wood is either integrated with } \\
\text { national commercial chains, or fed into large biomass (e.g., pelleting, } \\
\text { torrefaction, combined heat and power, power plants). It requires } \\
\text { high regional density. }\end{array}$ \\
\hline \multirow[t]{2}{*}{ Implementation } & $C R_{I \_C O M P}$ & $\begin{array}{l}\text { Competitiveness for the resource: discounts the percentage of } \\
\text { pruning wood that is being currently used for other purposes: } \\
\text { firewood, energy, etc. }\end{array}$ \\
\hline & $C R_{I_{-} \mathrm{OF}}$ & $\begin{array}{l}\text { Organic farming: assumed a default use for composting or other } \\
\text { in-farm activities. }\end{array}$ \\
\hline \multirow{5}{*}{ Sustainability } & $C R_{S_{-} E I A}$ & $\begin{array}{l}\text { The use of pruning wood should be compatible with Environmental } \\
\text { Impact Assessments (EIA). }\end{array}$ \\
\hline & $C R_{S \_S P A}$ & $\begin{array}{l}\text { Special Protection Areas: where biomass collection may be } \\
\text { constrained. }\end{array}$ \\
\hline & $C R_{S \_S O I L}$ & $\begin{array}{l}\text { Soil: part of the pruning that should be left on the soil to preserve } \\
\text { the soil organic carbon (SOC) in the soil in the long term. }\end{array}$ \\
\hline & $C R_{S_{-} G H G}$ & $\begin{array}{l}\text { The greenhouse gas (GHG) emissions have to comply with the } \\
\text { limits to be considered a renewable energy source. }\end{array}$ \\
\hline & $C R_{S \_O R I G I N}$ & $\begin{array}{c}\text { Pruning wood should not be imported or should not be sourced } \\
\text { from areas endangering the habitats. }\end{array}$ \\
\hline
\end{tabular}

\subsection{Assessment of Theoretical Potential}

Theoretical potentials of agricultural residues are usually calculated on the base of biomass productivity ratios [20,26,27], either residue to product ratios called RPR (expressing the weight of residue in relation to the main agricultural product), or residue to surface ratios denoted RSR (expressing the weight of residue obtained per hectare of cultivated land). The present work utilises the RSR ratios obtained by García-Galindo et al. [27] in a recent innovative approach. The aforementioned research work obtained average values of RSR (expressed in tons per hectare of dry matter) per EU28 regional units: NUTs0 (EU28 member states), NUTs2 (basic regions for the application of regional policies) and NUTs3 (smaller administrative regions). These ratios were obtained from a statistical analysis which demonstrated a moderate correlation of the RSR values (obtained by survey and literature research) with climatic, agro-climatic and agro-ecological factors. The ratios were obtained in the form of continuous geographical information systems (GIS) raster coverages, and were averaged by regional units by applying zonal statistic algorithms. 
García-Galindo et al. [27] provided the values of RSR ratios by NUTs units for five crop groups (vineyard, olive, fruit species, citrus and nuts) and under rainfed and irrigated conditions. Theoretical biomass was calculated by NUTs2 units according to the formula:

$$
\mathrm{Bio}_{T H_{[N U T 2]}}=\sum_{\text {Crop i }}^{n}\left[\text { Area }_{[N U T 2]}^{i} \times\left(I R R_{[N U T 2]}^{i} \times R S R_{I R R_{[N U T 2]}}^{i}+\left(1-I R R_{[N U T 2]}^{i}\right) \times R S R_{R F E D_{[N U T 2]}^{i}}^{i}\right)\right]
$$

where for a specific crop group $i$ Area[NUT2] is the total cultivated land of the crop in the land unit NUT2, $I R R_{[N U T 2]}^{i}$ is the share of land irrigated of this crop, $R S R_{I R R_{[N U T 2]}^{i}}^{i}$ and $R S R_{R F E D_{[N U T 2]}^{i}}$ are the productivity ratios per unit of land area $\left(\mathrm{tDM} \cdot \mathrm{ha}^{-1}\right)$ under irrigated or rainfed conditions respectively (provided in the Supplementary Materials of the mentioned work [27]). The data on cultivated land was provided by Eurostat for the five crop groups by NUTs3 for the year 2010 [28]). Germany is excluded as NUTs3 in this country are very small geographical units in comparison to other countries and for which no data on cultivated land was available from EUROSTAT by NUTs3. Therefore, in this case the land data was aggregated by NUTs2 for the calculations. The share of irrigated land by crop group (IRR $\left.{ }_{[N U T 2]}^{i}\right)$ was obtained from publicly available Eurostat [29] databases by NUTs2.

Biomass assessments by NUTs3 required a downscaling of the irrigation land share for each crop, since the EUROSTAT database did not provide data on irrigation share by NUTs3 (only by NUTs2) for the five crop groups object of study. The downscaling was simply performed by assigning the value of $\mathrm{IRR}_{\text {[NUT2] }}$ to the NUTs 3 contained in the NUT2 unit. The biomass theoretical potential for a NUTs3 unit was calculated as expressed in the following formula:

$$
\mathrm{Bio}_{T H_{[\mathrm{NUT3}]}}=\sum_{\text {Crop i }}^{n}\left[\operatorname{Area}_{[\mathrm{NUT3}]}^{i} \times\left(\operatorname{IRR}_{\left[\mathrm{NUT2}_{3}\right]}^{i} \times \operatorname{RSR}_{\text {IRR }}^{i}{ }_{[\mathrm{NUT3}]}+\left(1-\mathrm{IRR}_{\left[\mathrm{NUT2}_{3}\right]}^{i}\right) \times \operatorname{RSR}_{R F E D_{[N U T 3]}^{i}}^{i}\right)\right]
$$

where the terms can be read similarly to those described for Equation (3), except $I R R_{\left[N U T 2_{3}\right]}^{i}$, which denotes the share of irrigation for the crop group $i$ in the NUTs 3 unit according to the value of the NUT2 unit to which it corresponds.

The software QGIS v2.14-Essen (Open Source Geospatial Foundation, Beaverton, US) has been utilised to append the values of theoretical biomass potentials (obtained by NUTs2 and NUTs3) to the corresponding geographical coverages in order to produce visual representations of the results.

The procedure included a modification of the RSR values in NUTs units where Eurostat reported the existence of cultivated land for a crop group whilst the value of the RSR provided by García-Galindo et al. [27] was zero. In such cases the average ratios found for irrigation $\left(R S R_{I R R}\right)$ were lowered by a factor of 0.84 to obtain the value of $R S R_{R F E D}$, as well.

\subsection{Assessment of Technical Potential}

Technical potential is obtained from the theoretical biomass potentials lowered by two reduction factors (Table 1): $C R_{T_{-} L O S S}$ and $C R_{T \_S L O P E}$.

\subsection{1. $C R_{T_{-} L O S S}$}

Pruning harvesters have a limited capacity to perform a complete collection of the woody pruning residues. Predicting the harvesting losses caused by the technical limitations of the machinery is rather complex, specially taking into account the scale of the assessment. It is hypothesized that farmers and service companies prepare properly the field to perform the collection. Hence, the losses to be expected are low, only those derived from a limitation of the pick-up system, but not derived from a wrong operation or an improper field preparation. To obtain a set of coefficients of reduction, the values of performance tests of pruning harvesting machinery reported in specialised literature have been consulted. The values of $C R_{T_{-} L O S S}$ for the five crop groups targeted are assigned as shown in Table 2 . 
Table 2. $C R_{T_{-} L O S S}$ values assigned by crop group.

\begin{tabular}{lcc}
\hline \multicolumn{1}{c}{ Crop Groups } & CR $_{T_{-} \text {LOSS }}$ & Sources \\
\hline Vineyard & 0.12 & {$[30,31]$} \\
Olive & 0.04 & {$[32-34]$} \\
Pome fruit and citrus fruit & 0.08 & {$[35,36]$} \\
Fruit (except apple) & 0.10 & {$[30,37]$} \\
Nuts & 0.10 & {$[30,38]$} \\
\hline
\end{tabular}

Losses could have been modelled according to some parameters like slope (the steeper the field, the more difficult the operations to collect the pruning). The pruning harvesting losses are, furthermore, affected by the type of machine used and its pick up system can influence the harvesting, the pruning characteristics (pruning size), how the pruning is situated (if the pruning is prepared previously in windrows, or if the pruning is uniformly distributed, the losses vary quite a lot), the stoniness, the height of the grass at the moment of collecting the pruning, or the ability of the driver. Building complex models or scenarios does not ensure an appropriate result. Furthermore, the data on which the models would rely on are usually not available at large scale, but only locally. In this work, however, the CR values have been selected as constant values for the whole of Europe.

\subsection{2. $C R_{T \_S L O P E}$}

Harvesting losses increase as slope does. In the case of fields with more than 5 degrees' slope, the harvesting losses might be set as 15\% according to diverse experiences [39,40]. Preparing a model of losses should include dedicated inputs of the type of machinery utilised, the type of pruning preparation and pruning size and shape, and intensive field data. Such detailed implementation is beyond large-scale assessments. This work has selected slopes of maximum $20 \%$ slope as a limiting factor for the collection of pruning wood.

Preparation of $C R_{T \_S L O P E}$ average values by NUTS2 and NUTs3 units has relied on the interpretation of DEMs (digital elevation models) for the EU28. The SRTM (Shuttle Radar Topographic Mission) and CIAT V4 DEM [41] has been utilised for this purpose. This version provides at $1 \times 1 \mathrm{~km}$ grid cell. The grid has been intersected with the land uses for permanent crops provided by CORINE Land Cover v17 [42] at grid cells of size $0.25 \times 0.25 \mathrm{~km}$. QGIS 2.14.0-Essen software has been utilised for masking the DEM with the Land Use Cover classes 221 (vineyards), 222 (fruit trees and berry plantations), 223 (olive groves), 241 (annual crops associated with permanent crops). QGIS zonal statistics algorithm has been applied to obtain the average slope of permanent crops by NUTs3 and NUTs2. $C R_{T \_S L O P E}$ by each geographical unit has been calculated as the division between the number of pixels inside the mask of the four CORINE classes which value is above 0.2 (meaning 20\%), and the total number of pixels of the mask. A single value of $C R_{T \_S L O P E}$ by NUTs unit is obtained for five crop groups as a whole.

\subsection{Assessment of Economic Potential}

Economic potentials are implemented in multiple biomass research assessments on the base of a study of biomass costs of supply. In large-scale studies, models cannot capture details of local realities and markets. Therefore, the outputs of such models are to be interpreted as guidance or rule of thumb, and especially as a way to understand differences between regions, tendencies, or regionally more appropriate supply schemes (among others).

Pruning from permanent crops (olive, grape and fruit) is a special case since the number of existing value chains is very limited. Not only the market, but other social or conjectural reasons-like regulations hindering the disposal of pruning in open fires, social pressure, interest to brand the clean image of a region or company - are behind the development of multiple pruning in energy value chains $[23,43]$. Furthermore, the format of the value chains depends much on the size of the supply, willingness of farmers to participate and modify their usual disposal methods, and the size and layout 
of crop fields-which determines the type of harvesting and subsequent alternatives for the value chain. As the pruning value chains are not standardised, developing models on costs for large scale assessments of economic potentials may be a non-practical approach.

This work presents as an alternative the assessment of the economic potentials on the base of existing pruning biomass exploitation models instead of according to the costs of the supply. These models have been collected and analysed by the EuroPruning [23] and the uP_running project [43,44] Therefore, the scope is to provide CRs foreseen the part of the technical potential that can be utilised for energy according to different modes of exploitation.

Based on the organisational models of the value chains $[23,39,43-45]$ a total of five principal cases have been identified, as presented in Table 3. The definition of the five models under which pruning exploitation is arranged in the present work is discussed in the next sections.

Table 3. Limitations of CRs for economic potentials evaluation.

\begin{tabular}{|c|c|c|c|}
\hline $\begin{array}{l}\text { Coefficient of } \\
\text { Reduction }\end{array}$ & Description & Request on Farm Size & $\begin{array}{c}\text { Request on Biomass } \\
\text { Density }\end{array}$ \\
\hline$C R_{E_{-} W A S T E}$ & $\begin{array}{c}\text { No economic } \\
\text { limitation-assuming all } \\
\text { technical potential is } \\
\text { economical. }\end{array}$ & - & - \\
\hline$C R_{E \_S E L F}$ & $\begin{array}{l}\text { Self-consumption scenario: } \\
\text { fields with size under } 2 \text { ha not } \\
\text { exploitable-self-consumption } \\
\text { requires farm size }>2 \text { ha. }\end{array}$ & $>2$ ha & - \\
\hline$C R_{E_{-} C O M-S}$ & $\begin{array}{l}\text { Commercial at small scale: } \\
\text { representing local value chains } \\
\text { with a local service company } \\
\text { collecting and treating a } \\
\text { minimum of } 800 \mathrm{t} \text { of dry } \\
\text { matter in a neighbourhood of } \\
5 \mathrm{~km} \text { radius. }\end{array}$ & $>2$ ha & $\begin{array}{l}\text { More than } 800 \mathrm{tDM} \text { in } \\
5 \mathrm{~km} \text { radius }\end{array}$ \\
\hline$C R_{E_{-} C O M-M}$ & $\begin{array}{l}\text { Commercial at medium scale: } \\
\text { representing local value chains } \\
\text { where a local service company } \\
\text { or a final consumer organises } \\
\text { the collection of pruning } \\
\text { biomass for a medium size } \\
\text { application- } 4000 \mathrm{t} \text { of dry } \\
\text { matter in } 10 \mathrm{~km} \text { distance. }\end{array}$ & $>2$ ha & $\begin{array}{l}\text { More than } 4000 \mathrm{tDM} \text { in } \\
10 \mathrm{~km} \text { radius }\end{array}$ \\
\hline$C R_{E_{-} C O M-L}$ & $\begin{array}{l}\text { Commercial at large scale: } \\
\text { pruning wood integrated with } \\
\text { national commercial chains or } \\
\text { feeding large biomass-e.g., } \\
\text { pelleting, torrefaction, CHPs, } \\
\text { power plants. Requires high } \\
\text { regional density-10,000 t of } \\
\text { dry matter in } 20 \mathrm{~km} \text { radius. }\end{array}$ & $>2$ ha & $\begin{array}{c}\text { More than } 10,000 \mathrm{tDM} \text { in } \\
20 \mathrm{~km} \text { radius }\end{array}$ \\
\hline
\end{tabular}

\subsection{1. $C R_{E_{-} W A S T E}$-Scenario of Pruning Handling under a Waste Management Scheme}

The examination of the multiple exploitation models of the existing pruning value chains $[23,39,43-45]$ suggests that even under uneconomic harvesting practices, pruning is collected driven by regulations in force or by strong environmental or social interest. Under this scenario, all the technically collectable potential is considered as available for use and thus $C R_{E_{-} W A S T E}=0$ is assigned to all NUTs units. 


\subsection{2. $C R_{E \_S E L F}$-Scenario for Self-Consumption}

This is the least constraining case for economic use of the pruning wood whenever there is not a waste management regulation triggering the harvesting of prunings. Self-consumption implies the more simple value chain, where there is no transfer of any residue. A farmer, cooperative, or plantation manager is the sole actor deciding the adoption of a new agricultural practice in handling the pruning residues, and its new fate or role. Self-consumption includes small biomass consumption-the case of smallholders-as well as large biomass heating or CHP (combined heating and power) facilities. The restriction applied here is the size of the exploitation size. It is considered that ownership smaller than 2 ha is not of interest for self-consumption. A field of 2 ha can easily yield at least $1 \mathrm{tDM} \cdot \mathrm{ha}^{-1}$ of annual pruning (as proposed in [18]) and thus provide energy equivalent to 500 litres of gasoil, sufficient amount for covering the heating demand of a small household. Pruning transformation can be performed in a traditional way to produce firewood out of the thicker parts of the branches-the most extended traditional use of pruning - but can also be an object of mechanical collection and treatment like in case of Riolo Terme (Emilia Romagna, Italy) [46] using a small pruning harvester, Chateau Poupille (Aquitaine, France) [46] with external service, or by renting a manually-fed chipper, as in the cases of Agrifranja [46] or Casa Miquelas in Fraga, Spain [43]. Self-consumption in larger scale is documented for multiple experiences of agro-cooperatives and agro-industries like Cantine Giorgo Lungarotti (Perugia, Italy), Vesterled Frugtplant (Fejø, Denmark), Rolniczo-Sadownicze Gospodarstwo Doświadczalne Przybroda (in Rokietnica, Poland), Gospodarstwo Sadownicze (Wieniawa, Poland) [46] and ITC Shabo winery (Odessa Oblast, Ukraine) [44]. In all these cases, the area collected is above 50 hectares, being the biomass used principally in self-consumption.

In order to implement the scenario, the input data has been obtained by NUTs2 from the Eurostat regional statistics [29]. This data set provides the total cropped area by crop groups at several intervals of farm size. The area corresponding to farm size smaller than 2 hectares has been screened out. For every crop group - vineyards, olive, fruit species, citrus and nuts-the value of $C R_{E_{-} S E L F}$ is calculated for each NUT2s unit as the relation between the hectares whose ownership is larger than 2 hectares, and the total cultivated area. The values are downscaled to NUTs3 by assigning to each NUTs 3 unit the $C R_{E \_} S E L F$ value of the NUTs2 containing it.

\subsection{3. $C R_{E_{-} C O M-S}$-Scenario of Small Commercial Value Chains}

Establishing a value chain of small scale requires a minimum amount of biomass to be collected. Facing the investment in new machinery and on new handling or storage facilities require a minimum volume of biomass to be collected annually. According to EuroPruning surveying and analysis of 19 case studies and 7 hypothetical cases, a service company acquiring a new pruning biomass harvester require utilisation of minimum of working hours per year of 400 to $600 \mathrm{~h}$ to allow a reasonable amortisation period [23]. It is advisable to count with at least a minimum amount of biomass per hectare to allow a positive economic balance. It is also crucial efficient harvesting of the pruning in order to have a reasonable returning period of the investment, the biomass field capacity production should be of at least at $1 \mathrm{t} \cdot \mathrm{h}^{-1}$ [47]. The larger the field capacity, the better the economics. Starting from this figure, a minimum of 400 to $600 \mathrm{t}$ of the fresh matter is needed to be collected to make feasible this type of initiative. Some initiatives fitting under this model are Vilafranca del Penedes town [44] or Bodegas Torres [48] (both on vineyards and sited in Spain).

The scenario of small commercial value chain includes as request a minimum threshold of $800 \mathrm{tDM}$ - tons of dry matter - of the theoretical potential in a radius of $5 \mathrm{~km}$, as it is considered a local potential triggering the start-up of the new value chain. The implementation of this scenario has been undertaken with the geographical analysis tools of QGIS2.14.0-Essen. The vector of geographical coverage of NUTs2 - whose attributes table contains the values of the pruning theoretical potentials-has been intersected with the shape of the permanent crops of cultivated land in Corine Land Cover [42] land-use classes 221, 222, 223, 241. The theoretical potential is then divided by the number of Corine Land Cover pixels inside the NUTs2 to obtain an average pruning potential density. These raster coverages have 
been set to a grid pixel size of $250 \mathrm{~m}$. The biomass density value has been assigned to each pixel with the raster calculation tool. By means of the QGIS neighbourhood statistics tool every grid cell in the European map has been assigned with the sum of the values of all the pixels in a neighbourhood of $5 \mathrm{~km}$ radius. The result is a grip map of Europe with a total theoretical pruning potential collectable in a radius of $5 \mathrm{~km}$. A raster calculation is then applied to screen out the grid cells where the value of the pixel is lower than $800 \mathrm{tDM}$. Comparing the total number of remaining pixels per NUTs2 (zonal statistics tool) with the total pixels inside the NUTs2 unit, the value of $C R_{E_{-} C O M-S}$ in each geographical unit is assessed. Downscaling to NUTs3 is performed by assigning the $C R_{E_{-} C O M-S}$ value of the NUTs2, to each NUTs3 unit contained in it.

\subsection{4. $C R_{E_{-} C O M-M}$-Scenario of Medium Commercial Value Chains}

Medium-sized pruning value chains occur in areas where there is a special dedication to produce fruits, grapes or olives. The local concentration of fields creates the opportunity to coordinate the collection of biomass. Even several companies may cooperate or compete. The biomass can be utilised for multiple purposes and distributed to several users, or may be centralised and delivered to a single specific consumer. Logistics remain local or regional, and conversion to pellets or other intermediate bio-commodities may take place, in small plants forming part of a network of large value-chain distribution-even though at the present moment pruning residues commercialized in this medium scale is predominantly consumed locally. Several cases representative of this model are that of Miajadas (in Extremadura, Spain) or Trzebnica (in Trzebnica, Poland) as presented by EuroPruning [23]. In both cases, the pruning is pushed to the field side, and a local logistic operator uses industrial shredders or forestry chippers mounted on a truck to obtain shredded wood (hog fuel) ready to send directly to a medium/large final consumer (reaching distances of 80 and up to $200 \mathrm{~km}$, respectively). The case of Vilafranca del Penedés where several suppliers with several machines are covering the consumption of two caves (Bodegas Torres and Cavas Vilarnau) and a city council district heating newly built in Vilafranca del Penedes town [44]. A similar case is the Fiusis gasification plant-as described by the uP_running in [44] — sited in Calimera city (Puglia region in Italy) which consumes a total of $8000 \mathrm{tDM}$ of olive pruning wood gathered in a radius of $10 \mathrm{~km}$.

The medium-size economic scenario is defined under two characteristics: land under 2 hectares is not considered as a potential supplier; and theoretical potential of more than $4000 \mathrm{tDM}$ of pruning biomass in the area of $10 \mathrm{~km}$ radius. The methodology followed to implement $C R_{E_{-} C O M-M}$ is equivalent to the methods described previously for $C R_{E_{-} C O M-S}$ assessment. The only difference is the size of the radius of $10 \mathrm{~km}$ for implementing the neighbourhood statistics.

\subsection{5. $C R_{E_{-} C O M-L}-$ Scenario of Large Commercial Value Chains}

Large-scale consumption of pruning biomass is carried out in large areas where vineyards, olive or fruit are a predominant part of the landscape. Examples—described by EuroPruning [23] — have been found in Spain for olive pruning in Andalusia, with cases like the power plants of Sacyr Energía Puente Genil (power of 9.7 MW) sited in Córdoba province, or Linares (15 MW of power) sited in Jaen Province, as well the five power plants of the cooperative El Tejar sited in Baena, Palenciana, and El Tejar (in Córdoba province). Those plants consume more than 30,000 t of fresh matter per year, and the procurement is quite varied: from local farmers bringing their biomass, to specialised local service companies carrying out the collection with integrated pruning harvesters. Another case is ENCE—a pulp-producing group with several power plants in Spain-power plant sited in Merida, which consumes currently more than 20,000 t of pruning and plantation removal wood from olive, fruits and vineyards. In all the aforementioned cases the supply distance considered is less than $50 \mathrm{~km}[45]$.

Production of energy carriers (pellets) for local and long distance distribution is also a fact, even though not expanded. The Jabalquinto cooperative [23] produces olive pruning pellets. The processing capacity is about $10 \mathrm{kt}$ of finished product yearly and the area of the collection is about $15 \mathrm{~km}$ radius. 
Pellets de la Mancha produce yearly circa $20 \mathrm{kt}$ of finished pellets made out of vineyard prunings collected in $30 \mathrm{~km}$ radius [44].

In order to model the scenario of large-scale value chains it is requested to accomplish two conditions: land teenage under 2 hectares not considered as a potential supplier; and a theoretical pruning biomass potential of at least $10,000 \mathrm{tDM}$ in a radius of $20 \mathrm{~km}$. The methodology followed to implement $C R_{E_{-} C O M-L}$ is equivalent to that described for the $C R_{E_{-} C O M-S}$ assessment. The only difference lays on the size of the radius amounted $20 \mathrm{~km}$ for implementing the neighbourhood statistics, and on the threshold of 10,000 $\mathrm{t}$ of biomass counted inside the $20 \mathrm{~km}$ radius to consider a grid cell as compatible with large-scale pruning exploitation.

\subsection{Assessment of Implementation Potential}

Implementation potentials have considered two socio-economic constraints that may limit the economically affordable biomass. $C R_{I_{-} C O M P}$ reduces the biomass potential to include competitiveness as a limiting factor, since targeting biomass already in use shall cause sudden increments in the market price. $C R_{I_{-} O F}$ considers that under organic farming the in-farm composting and use of the pruning may be considered by default as the best practice instead of a collection of the pruning in order to be used in an external energy facility.

\subsection{1. $C R_{I-C O M P E T}$}

The competitive uses for agricultural pruning wood have been widely described in EuroPruning [49] for a total of 11 European countries: Spain, Italy, France, Greece, Germany, Netherlands, Austria, Slovenia, Poland, Slovakia and Ukraine. The current pruning management and fate are well described, being principally: disposal at field side, burning in the open air at the field or at field side, mulching of the pruning to the soil, use as firewood, and use for energy. Disposal at the field side or destruction in fires (piles of branches at the field or field side) have been considered non-competitive uses, whereas the use as firewood or as an energy feedstock is considered as competitive. Mulching, in contrast, presents a dichotomy. On the one hand mulching may have a positive effect on the soil, by improving its structure and organic matter content, thus representing a value for the farmer. On the other hand, mulching is regarded by multiple farmers as the simplest, straightest and low-cost method to manage this agricultural residue [49]. Mulching is a practice in expansion, but it does not necessarily mean that the availability of pruning will decrease. For example the current expansion of some diseases like Xylella fastidiosa (in olive groves and vinestocks) or Esca (black measles) is changing the perception of technicians and farmers in respect the best management methods of the pruning wood, as it can be a source for disease propagation. EuroPruning reports several areas where integrating the pruning wood to the soil is forbidden. On the other hand, there are other driving forces at European, national or regional level coming from the application of the Common Agricultural Policy Cross Compliance measures, particularly the Good Agricultural and Environmental Conditions (GAEC), which place requirements on farmers to maintain good soil quality, and maintain soil organic matter levels through measures such as banning the burning of arable stubbles.

According to these considerations, it has been decided not to consider mulching as a competitive use. The percentages reported in EuroPruning [49] as energy and firewood have been utilised to set a value of $C R_{I_{-} C O M P E T}$ per country. In cases of countries where this data was not reported by EuroPruning, the value of $C R_{I_{-} C O M P E T}$ has been assigned from the most similar or neighbouring country. Values of the CR expressed as a percentage are presented in Table 4. 
Table 4. CR implementation potentials averaged by country: competitiveness and organic farming.

\begin{tabular}{|c|c|c|c|c|c|c|c|c|c|c|c|c|}
\hline \multirow{2}{*}{ Country } & \multicolumn{6}{|c|}{$C R_{I \_C O M P E T}(\%)$} & \multicolumn{6}{|c|}{$C R_{I_{-} O F}(\%)$} \\
\hline & Fruit & Nuts & Citrus & Olive & Vine. & TOTAL & Fruit & Nuts & Citrus & Olive & Vine. & TOTAL \\
\hline AT & 0 & & & & 4 & 2.5 & 15.3 & & & & 7.3 & 10.3 \\
\hline BE & 1 & & & & & 1.0 & 1.6 & & & & & 1.6 \\
\hline BG & 7.75 & 2.5 & & & 2.5 & 5.5 & 6.7 & 0.0 & & & 0.8 & 4.1 \\
\hline $\mathrm{CY}$ & 10 & 20 & 0 & 30 & 10 & 13.6 & 3.5 & 0.0 & 1.7 & 8.7 & 2.4 & 4.1 \\
\hline $\mathrm{CZ}$ & 15 & & & & 0 & 10.9 & 20.0 & & & & 5.0 & 15.8 \\
\hline DE & 5 & 0.25 & & & 4 & 4.5 & 14.1 & 0.0 & & & 4.8 & 9.8 \\
\hline DK & 1 & 0.25 & & & & 1.0 & 18.0 & 0.0 & & & & 17.9 \\
\hline EE & 4 & & & & & 4.0 & 100.0 & & & & & 100.0 \\
\hline EL & 10 & 20 & 0 & 30 & 10 & 23.8 & 1.9 & 0.0 & 5.0 & 8.7 & 4.9 & 7.1 \\
\hline ES & 0 & 0 & 5 & 5 & 2 & 3.7 & 26.6 & 0.0 & 1.7 & 5.2 & 5.7 & 6.6 \\
\hline FI & 1 & & & & & 1.0 & 31.9 & & & & & 31.9 \\
\hline FR & 0.25 & 0.5 & 2.5 & 5 & 10.5 & 7.3 & 8.7 & 0.0 & 1.9 & 14.4 & 6.0 & 6.7 \\
\hline HR & 0.25 & 30 & 0 & 5 & 30 & 10.6 & 7.0 & 0.0 & 100.0 & 6.3 & 1.2 & 6.2 \\
\hline HU & 0 & 0 & & & 4 & 0.9 & 7.1 & 0.0 & & & 2.7 & 6.0 \\
\hline IE & 1 & & & & & 1.0 & 0.0 & & & & & 0.0 \\
\hline IT & 0 & 30 & 0 & 5 & 30 & 11.4 & 19.5 & 0.0 & 21.6 & 16.9 & 7.3 & 14.4 \\
\hline LT & 4 & 5 & & & & 4.0 & 44.8 & 0.0 & & & & 44.7 \\
\hline LU & 1 & & & & 10.5 & 9.1 & 23.1 & & & & 0.0 & 3.4 \\
\hline LV & 4 & & & & & 4.0 & 10.3 & & & & & 10.3 \\
\hline MT & 0 & & 0 & 5 & 30 & 12.3 & 0.0 & & 0.0 & 14.3 & 0.0 & 1.1 \\
\hline NL & 1 & 0.5 & & & 7.25 & 1.0 & 1.5 & 0.0 & & & 0.0 & 1.5 \\
\hline PL & 4 & 5 & & & 4 & 4.0 & 19.1 & 0.0 & & & 0.0 & 18.2 \\
\hline PT & 0 & 0 & 5 & 5 & 2 & 3.0 & 10.1 & 0.0 & 0.6 & 3.5 & 1.2 & 3.2 \\
\hline RO & 5 & 5 & & & 5 & 5.0 & 0.4 & 0.0 & & & 0.0 & 0.3 \\
\hline SE & 1 & & & & & 1.0 & 8.0 & & & & & 8.0 \\
\hline SI & 0.5 & 30 & & 5 & 17 & 8.1 & 10.1 & 0.0 & & 15.8 & 2.1 & 6.6 \\
\hline SK & 15 & 0 & & & 0 & 8.6 & 12.7 & 0.0 & & & 0.0 & 7.3 \\
\hline UK & 1 & & & & 10.5 & 1.3 & 5.3 & & & & 0.0 & 5.2 \\
\hline EU28 & 93 & 149 & 13 & 95 & 193 & 7.5 & 14.5 & 0.0 & 6.9 & 8.2 & 5.5 & 8.6 \\
\hline
\end{tabular}

\subsection{2. $C R_{I_{-} O F}$}

The potential implementation of pruning biomass value chains is subject to further reduction when considering organic farming. It is hypothesised that in farms following organic farming (OF) agronomics, the default use of pruning wood will be the integration into the soil or the in-farm composting. The implementation of $\mathrm{CR}_{\mathrm{I}-\mathrm{OF}}$ has based on the input data obtained by NUTs 2 from the regional statistics by NUTs classification of Eurostat [29]. The coefficient of reduction has been calculated by NUTs 2 and by crop group as the share of the area under OF with respect to the total area cropped by the crop group. It should be noticed that OF land in [29] are disaggregated by farm size, thus allowing a more tailored assignment of the $C R$ value by considering only the OF land in farm sizes larger than 2 hectares in the non-waste economic scenarios. The values by NUTs2 and NUTs3 are presented in Supplementary Materials Tables S2 and S3. The average coefficients by NUTs0 are presented in Table 4.

\subsection{Assessment of Sustainable Potential}

Sustainability criteria may constrain the current or future agricultural pruning biomass. If not sustainability is not accomplished, this feedstock, or a at least a part of its potential, could be considered as not renewable, and thus its use restricted, or not eligible for funds reserved for renewable energy promotion.

Formulation of constraints to the implementation potential at the EU28 scale should take into consideration the multiple sustainability issues considered in existing or coming regulations. In the European framework the European Commission establishes the guidelines on sustainability criteria on biomass and biofuels [50] that have been included as a requirement for biomass to be considered as 
eligible for public support in Directive (EU) 2018/2001 on the promotion of the use of energy from renewable sources [3]. These guidelines refer to the following items:

1. forbid the use of biomass from land converted from forest, and other high carbon stock areas, as well as highly biodiverse areas;

2. ensure that biomass utilised to provide sufficient reductions of greenhouse gases (GHG) over their lifecycle when compared to fossil fuels;

3. encourage the monitoring of the origin of all biomass consumed in the EU.

The utilisation of bioenergy in the short term is, therefore, the subject of a well-defined framework under which the implementation potentials must be interpreted. The current work defines a set of CRs accordingly. The quantification of the CRs proposed is described in this section. Values are proposed when the expected compliance of pruning can be easily assessed. For some of the sustainability items, any assessment should base on complex modelling or calculations. In such cases, the present section indicates this and the potential values of the $\mathrm{CR}$ are described in the section of discussion.

\subsection{1. $C R_{S_{-} E I A}$}

The environmental compliance of agricultural pruning utilisation in the European framework can be assessed through a standardised instrument denominated the Environmental Impact Assessments (EIA). The EuroPruning project developed an assessment based on multiple interviews and on the observation of several demonstrations of pruning field harvesting and mobilisation [51]. The assessment on environmental impacts followed the Directive 97/11/EC on the assessment of the effects of certain public and private projects on the environment. It revealed that the short-term character of the necessary operations or activities to perform the pruning biomass collection and mobilisation results in the final environmental impact being very limited and does not influence negatively on the local environment. Therefore the proposed value for the assessment is $C R_{S_{-} E I A}=0$.

\subsection{2. $C R_{S \_S P A}$}

Agricultural pruning utilisation can be restricted in Special Protected Areas (SPA) like natural or national parks since it usually prohibited the exploitation of any internal resource-including residues-obtained in land conservation or maintenance works of these areas. The exploitation of agricultural pruning in other SPA figures for Sites of Community Importance-defined in the European Commission Habitats Directive 92/43/EEC — shall be the object of specific environmental permits, though not prohibited. Natural parks or protected areas with very restrictive conditions are usually not the objects of cultivation, and thus, this should not be considered a limitation in the large-scale analysis, even though particular areas could present some incompatibilities locally.

\subsection{3. $C R_{S \_S O I L}$}

Directive (EU) 2018/2001 declares that agricultural feedstock for the production of biofuels, bioliquids and biomass fuels (solid biomass) should be produced using practices that are consistent with the protection of soil quality and soil organic carbon. It further declares that soil quality and soil carbon should, therefore, be included in the monitoring systems of operators or national authorities. A path for implementation of constraints is based on existing regulations of compulsory mulching or integration of agricultural residues as green fertiliser. At the moment there compulsory regulations for integrating pruning into the soil based on a need to preserve the soil organic matter (SOM) have not been detected [49]. Currently, there is no evidence that the use of pruning as an organic amendment could become a compulsory or strongly supported practice for the long term. Under this scope, it could be considered $C R_{\text {S_SOIL }}=0$.

An alternative followed here is the review of the literature to find the recommended rates of pruning removal that are compatible with soil sustainability. These values may be generic, or the result of running complex models on soil dynamics. A discussion is included in Section 3.5.3. 


\subsection{4. $C R_{S_{-} G H G}$}

In terms of accomplishment of the target on GHG reductions set by the Directive (EU) 2018/2001, this requests at least $70 \%$ reduction for electricity, heating and cooling production in installations starting operation from 1 January 2021 until 31 December 2025, and 80\% for installations starting operation from 1 January 2026. The directive provides reference values of typical reductions of GHG for low bulk density agricultural residues between $93 \%$ and $95 \%$ for heat production, and between 90 and $92 \%$ for electricity generation. Assessing the greenhouse gas (GHG) emissions derived from the exploitation of agricultural pruning implies the evaluation of the energy costs and other impacts associated with a specific value chain. Each value chain will lead to different outputs of GHG emissions due to the different methods utilised in the harvesting stage, the different treatments performed, and the emissions caused by the transport (depending upon the commercial scale of the chain). It may be necessary to implement different scenarios and combine them to obtain an average expected value of emissions. This methodology could be replicated by NUTs unit, and thus widened to a EU28 reach. Such approach assessment is far beyond the limits of the present work. A set of simplified results can be obtained by comparing the literature values of the GHG emissions with the default values of GHG emissions of fossil fuels provided by the Directive (EU) 2018/2001. These results are discussed in Section 3.5.2.

\subsection{5. $C R_{S_{-} \text {ORIGIN }}$}

The origin of the biomass is an issue of current high relevance for Europe. Importing biomass feedstock or commodities which may be not compatible with the criteria on habitats preservation is not compatible with the sustainability guidelines of the European Union (as for example wood exploitation under unsustainable schemes leading to deforestation). Currently, there are methods for forestry wood certification in terms of origin and sustainability like that of the Forest Stewardship Council A.C. (FSC) although this method is not applicable to agricultural residues like pruning wood. Agricultural pruning is an endogenous resource. Its use is expected to remain local, even though in some areas where permanent crops are a prevailing part of the agricultural land, the pruning biomass could be integrated in other national biomass supplies (as described for the scenario of large commercial value chains in Section 2.4.4). Furthermore, pruning residues are not a cause of deforestation or any change of habitat, as this is a by-product of an agricultural activity. Therefore the sustainability in terms of the origin of the biomass does not constrain the use of pruning wood for energy. Accordingly the value proposed is $C R_{S_{-} O R I G I N}=0$.

\subsection{Estimation of Total Available Energy}

The biomass potentials obtained are expressed as tons of dry matter. The biomass is, however utilised with a certain amount of moisture. In the present assessment it is hypothesised that the pruning wood has a moisture content of $20 \%$ when fed into the energy system. The energy released in thermal processes utilised to valorise the pruning wood can be calculated through Equation (6):

$$
E_{B}=B i o_{D M} \times\left(\frac{100}{100-W}\right) \times L H V_{W}
$$

where $B i_{D M}$ is the biomass potential expressed as dry matter (no moisture content), $W$ is a moisture content in \%wt., $L H V_{W}$ is the lower heating value at a considered moisture content in the biomass. The LHV values utilised are provided in Table 5.

Table 5. Lower heating value (LHV) of the selected pruning wood [52].

\begin{tabular}{cccccc}
\hline LHV $\left(\mathbf{M J} \cdot \mathbf{k g}^{\mathbf{- 1}}\right)$ & Fruit & Nuts & Citrus & Olive & Vineyard \\
\hline$L H V_{D M}(W=0 \%)$ & 17.5 & 17.2 & 17.2 & 16.7 & 16.8 \\
$L H V_{W}(W=20 \%)$ & 13.5 & 13.3 & 13.3 & 12.9 & 13.0 \\
\hline
\end{tabular}




\section{Results and Discussion}

\subsection{Pruning Theoretical Potentials}

In Table 6 the results of the theoretical potentials by the EU28 member states are presented. These indicate that ca. 13.67 MtDM is produced annually in EU28. Vineyards are the crop group contributing the most to the theoretical potential, with a total of $5.47 \mathrm{MtDM} \cdot \mathrm{yr}^{-1}$. Nuts and olive pruning wood can contribute respectively with 3.44 and 3.22 $\mathrm{MtDM} \cdot \mathrm{yr}^{-1}$. Citrus and dry-nuts plantations contribute to a lesser extent with their corresponding subtotals of 0.90 and $0.63 \mathrm{MtDM} \cdot \mathrm{yr}^{-1}$. As can be observed, Spain and Italy-being Mediterranean countries with a large area-represent more than $50 \%$ of the EU28 pruning biomass theoretical potentials. Other countries with relevance are France and Greece, followed by Portugal, Poland, Romania, Hungary, Germany and Bulgaria.

Figure 2 depicts the distribution of the theoretical potentials by NUTs2 ( 275 geographical units). Further disaggregation by crop species is provided in supplementary material Figure S1. The visual results by NUTs3 (1341 geographical units) are presented in the supplementary material Figure S2. The tabulated results of CR and biomass potentials by NUTs0, NUTs2 and NUTs3 level can be consulted in supplementary material Tables S1 and S2, respectively.

If observed again in the NUTs2-level maps (Figure 2), the permanent crops are usually concentrated in specific country areas where the climatic conditions are more favourable for them. Therefore, even if the potentials in the whole country may be limited, the potentials can be very relevant regionally or locally and, thus, can be a resource of relevance for promoting local bioeconomy based on pruning wood.

Figure 2 shows an important part of the potential located in Mediterranean areas (details can be consulted in Tables S2 and S3 Supplementary Materials). France, Poland and Romania also show to have important potentials in their NUTs2 units. It must be observed that the size of NUTs2 is quite varied through the EU28 member states. The size of the NUTs2 units in Spain, France, Poland or Romania are quite large in comparison to the NUTs2 units in Germany or The Netherlands; e.g., It must be observed that the larger the size, also the larger the chance of higher potential, as the unit covers a larger geographical area.

When observing the theoretical potentials by NUTs3 (Figure S2) the prevailing role of permanent crop pruning as an energy resource is more evident. Spain, with the largest area of permanent crops in the EU28, and also NUTs3 units of large size in comparison to other countries, show the largest potentials (dark blue coloured units). Italy, Greece, Poland or Romania also show some of their units to have a relevant potential. It must be noted that in Figure S2 Germany is depicted as blank in terms of potentials because there was no data available for permanent crops areas at this geographical level. 
Table 6. Theoretical and technical biomass potential by crop group at NUTs0 (country level) in EU28 (mass and energy units).

\begin{tabular}{|c|c|c|c|c|c|c|c|c|c|c|c|c|c|}
\hline & \multirow{2}{*}{$\begin{array}{l}\text { Country } \\
\text { (NUTs0) }\end{array}$} & \multicolumn{6}{|c|}{$\mathrm{Bio}_{\mathrm{TH}}\left(\mathrm{tDM} \cdot \mathrm{yr}^{-1}\right)$} & \multicolumn{6}{|c|}{ Bio $_{\mathrm{T}}\left(\mathrm{tDM} \cdot \mathrm{yr}^{-1}\right)$} \\
\hline & & Fruit & Nuts & Citrus & Olive & Vineyard & TOTAL & Fruit & Nuts & Citrus & Olive & Vineyard & TOTAL \\
\hline AT & Austria & 27,428 & 0 & 0 & 0 & 49,080 & 76,509 & 24,959 & 0 & 0 & 0 & 43,185 & 68,144 \\
\hline BE & Belgium & 34,899 & 0 & 0 & 0 & 0 & 34,899 & 31,758 & 0 & 0 & 0 & 0 & 31,758 \\
\hline BG & Bulgaria & 81,776 & 7869 & 0 & 0 & 55,181 & 144,825 & 74,331 & 7075 & 0 & 0 & 48,496 & 129,902 \\
\hline $\mathrm{CY}$ & Chyprus & 9629 & 2978 & 11,900 & 16,373 & 9062 & 49,941 & 8690 & 2658 & 10,621 & 15,588 & 7908 & 45,465 \\
\hline $\mathrm{CZ}$ & Czechia & 36,307 & 0 & 0 & 0 & 15,058 & 51,365 & 33,040 & 0 & 0 & 0 & 13,251 & 46,291 \\
\hline $\mathrm{DE}$ & Germany & 110,917 & 354 & 0 & 0 & 102,120 & 213,391 & 100,935 & 319 & 0 & 0 & 89,866 & 191,119 \\
\hline DK & Denmark & 3261 & 5 & 0 & 0 & 0 & 3266 & 2968 & 5 & 0 & 0 & 0 & 2972 \\
\hline EE & Estonia & 1800 & 0 & 0 & 0 & 0 & 1800 & 1638 & 0 & 0 & 0 & 0 & 1638 \\
\hline EL & Greece & 177,701 & 22,502 & 76,227 & 932,835 & 106,975 & $1,316,240$ & 161,708 & 20,252 & 68,605 & 895,521 & 94,138 & $1,240,224$ \\
\hline ES & Spain & 478,130 & 329,151 & 545,869 & $2,749,597$ & 940,455 & $5,043,203$ & 429,624 & 295,291 & 489,292 & $2,625,290$ & 825,392 & $4,664,890$ \\
\hline FI & Finland & 1110 & 0 & 0 & 0 & 0 & 1110 & 831 & 0 & 0 & 0 & 0 & 831 \\
\hline FR & France & 346,063 & 27,966 & 13,600 & 20,933 & 879,061 & $1,287,624$ & 314,016 & 25,055 & 12,167 & 20,031 & 772,348 & $1,143,617$ \\
\hline HR & Croatia & 54,945 & 6526 & 2495 & 20,351 & 33,484 & 117,802 & 49,592 & 5859 & 2133 & 18,559 & 28,721 & 104,863 \\
\hline HU & Hungary & 187,547 & 6295 & 0 & 0 & 63,177 & 257,019 & 170,668 & 5665 & 0 & 0 & 55,596 & 231,929 \\
\hline IE & Ireland & 945 & 0 & 0 & 0 & 0 & 945 & 860 & 0 & 0 & 0 & 0 & 860 \\
\hline IT & Italy & 557,845 & 128,705 & 223,519 & $1,434,038$ & 789,241 & $3,133,348$ & 493,707 & 113,912 & 198,223 & $1,360,483$ & 682,719 & $2,849,044$ \\
\hline LT & Lithuania & 20,621 & 74 & 0 & 0 & 0 & 20,695 & 18,766 & 66 & 0 & 0 & 0 & 18,832 \\
\hline LU & Luxembourg & 208 & 0 & 0 & 0 & 1337 & 1545 & 189 & 0 & 0 & 0 & 1177 & 1366 \\
\hline LV & Latvia & 9679 & 0 & 0 & 0 & 0 & 9679 & 8808 & 0 & 0 & 0 & 0 & 8808 \\
\hline MT & Malta & 951 & 0 & 415 & 201 & 932 & 2499 & 865 & 0 & 374 & 193 & 820 & 2252 \\
\hline NL & Netherlands & 30,808 & 12 & 0 & 0 & 63 & 30,884 & 28,008 & 11 & 0 & 0 & 56 & 28,075 \\
\hline PL & Poland & 556,495 & 25,551 & 0 & 0 & 284 & 582,330 & 506,253 & 22,933 & 0 & 0 & 250 & 529,436 \\
\hline PT & Portugal & 84,853 & 76,276 & 27,805 & 294,292 & 199,513 & 682,739 & 76,237 & 68,341 & 24,882 & 281,677 & 174,348 & 625,484 \\
\hline RO & Romania & 336,424 & 1628 & 0 & 0 & 169,933 & 507,985 & 306,050 & 1464 & 0 & 0 & 149,519 & 457,032 \\
\hline SE & Sweden & 2844 & 0 & 0 & 0 & 0 & 2844 & 2582 & 0 & 0 & 0 & 0 & 2582 \\
\hline SI & Slovenia & 19,931 & 567 & 0 & 994 & 17,396 & 38,888 & 18,017 & 507 & 0 & 948 & 15,206 & 34,678 \\
\hline SK & Slovakia & 15,275 & 177 & 0 & 0 & 11,583 & 27,035 & 13,898 & 159 & 0 & 0 & 10,191 & 24,248 \\
\hline UK & United Kingdom & 34,917 & 0 & 0 & 0 & 1014 & 35,931 & 31,714 & 0 & 0 & 0 & 891 & 32,606 \\
\hline \multirow{2}{*}{ EU28 } & Mass (tDM·yr ${ }^{-1}$ ) & $3,223,310$ & 636,636 & 901,830 & $5,469,614$ & $3,444,951$ & $13,676,341$ & $2,910,710$ & 569,572 & 806,297 & $5,218,291$ & $3,014,077$ & $12,518,946$ \\
\hline & Energy $\left(\mathrm{PJ} \cdot \mathrm{yr}^{-1}\right)$ * & 53.5 & 10.3 & 14.5 & 90.7 & 58.2 & 227.2 & 48.3 & 9.2 & 13.0 & 86.6 & 50.9 & 207.9 \\
\hline
\end{tabular}

$(*)$ Energy calculated as the energy released in combustion of the biomass with $20 \%$ moisture. 


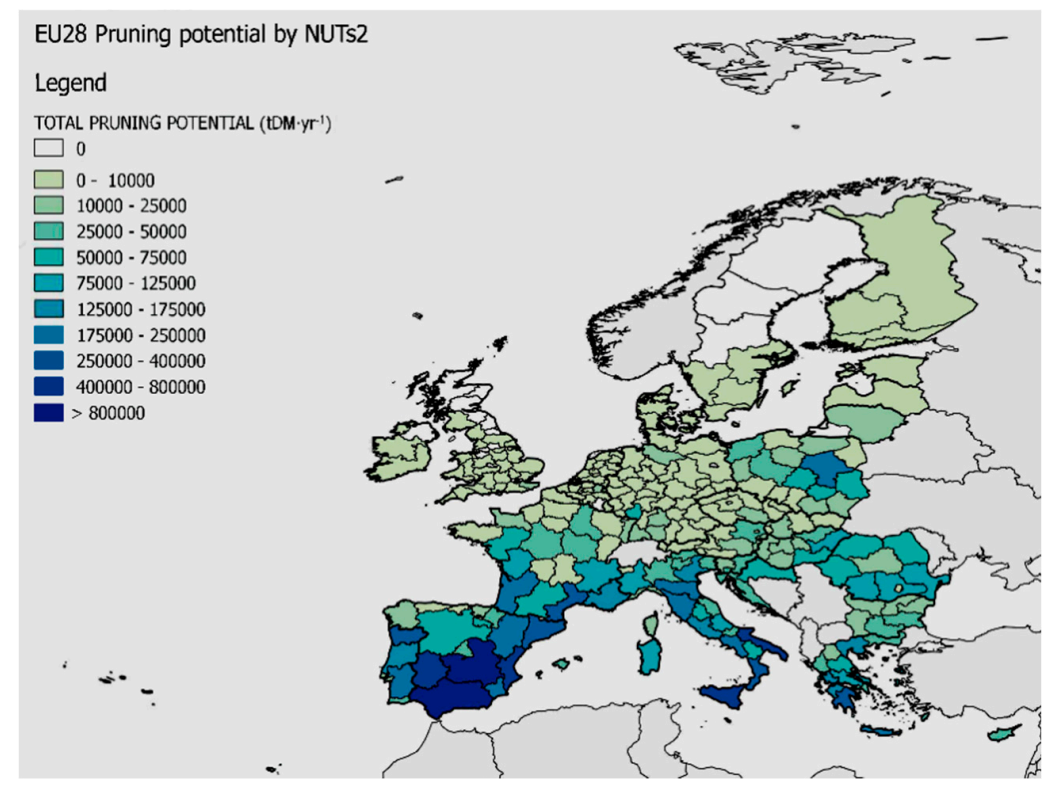

(a)

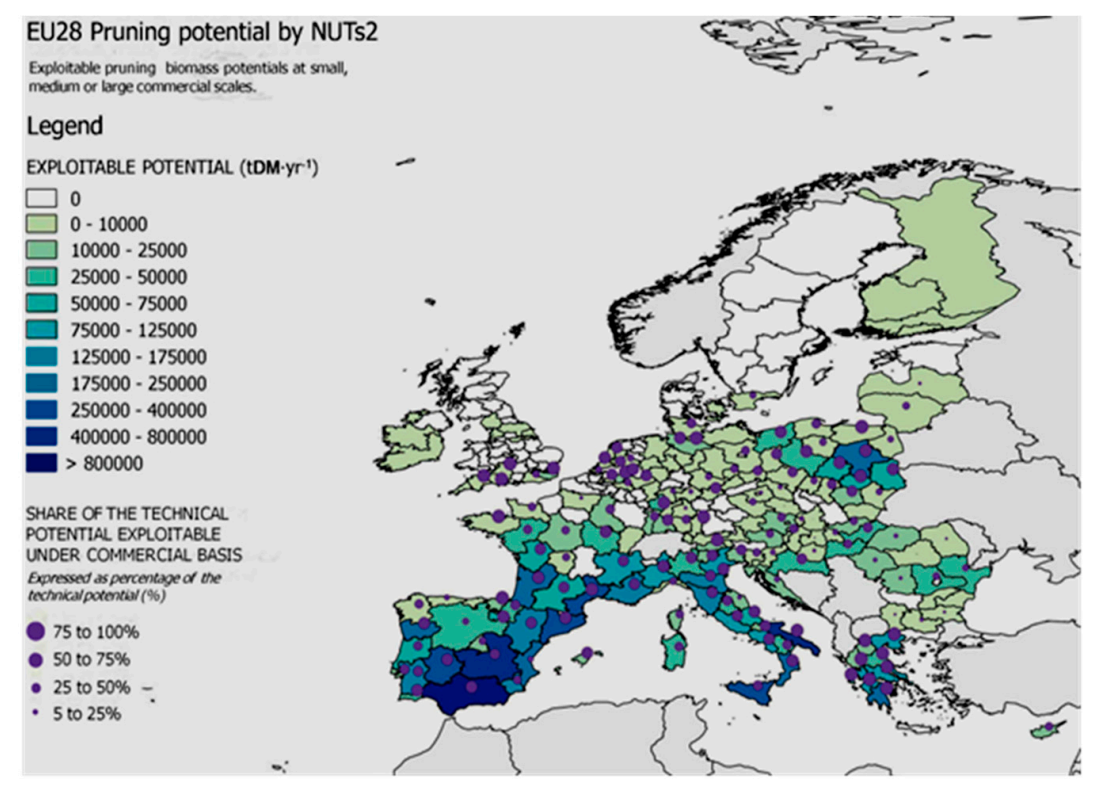

(b)

Figure 2. Total agricultural pruning potential in EU28 by NUTs2 geographical units. (a) Theoretical potentials. (b) Economic potentials exploitable under market demand.

\subsection{Pruning Technical Potentials}

Results are presented in Table 6 by NUTs 0 (further details in Table S1), and in Tables S1 and S2 by NUTs2 and NUTs3 respectively. As observed, the technical limitations applied, lead to a small reduction of the potentials. The combined coefficients of reduction-harvesting losses and slope are in all cases under $12 \%$ (except Finland). The overall reduction due to technical constraints in $\mathrm{EU} 28$ is $8.5 \%$. Therefore the EU28 technical pruning potentials still remain quite high, about $12.5 \mathrm{Mt}$ of pruning wood dry matter achievable per year. The countries with the greatest pruned biomass potential are Spain, Italy, France and Greece which provide ca. $80 \%$ of the total EU 28 technical potential. It is characteristic that the leading countries are located in the Mediterranean climate favouring the cultivation of permanent crops plantations/orchards. 
In respect to the technical limitations to collect the biomass and avoid harvesting losses, several sources indicate that harvesting machineries have a limited capacity to perform a complete collection of the wood pruning residues [53]. Several reasons are the height of the pick-up system [54], the width of the crop lanes and the previous preparation of the material on the field $[25,30]$ the use of windrowers to increase the operation range of the harvesting machinery $[27,53]$ withdrawal of large pieces of branches, the conditions of the terrain (slope, stoniness, grass cover, uneven soil surface). Moreover, the type of applied harvesting technology/machinery and the experience of the machinery operator play a relevant role. The applied CRs correspond to a unique value of the coefficient by crop and for the whole of Europe (see Table 2). The modelling is very simplistic for the complexity of the process that is the object of quantification. Alternatives could be a weighting of the value of losses according to the slope, type of pruning or typical soil management. However this type of assessment is more in line with local assessments, as for a EU28 assessment the data necessary to be utilised for such modelling are not existing or not available by NUTs2.

In terms of slope, only in a few NUTs 2 and NUTs 3 units was the slope intersecting the CORINE land cover larger than $20 \%$. Forestry areas or bare or rock mountains may have led to larger slopes. However the land inside the land use of permanent crops is in general under $20 \%$ slope. As a consequence, almost no reduction for most of the NUTs2 units due to slope was detected. This restriction however, if applied at smaller scale and with more precise DEMs, would lead to a larger reduction in the technical potentials in geographical units with hilly areas.

S2Biom provided in the 2017 results on agricultural pruning biomass potentials [22]. The original data based partly on national average RSR pruning productivity ratios and partly on the elaboration from the base of EuroPruning surveys [49]. The data surveys were mostly independent of the data sources utilised to find the theoretical potentials of the present article-based on RSR values obtained by NUTs2 as explained in a work preceding the present article [18]. S2Biom technical constraints applied based on the pruning collection losses, thus not including slope. The land was evaluated based on Eurostat records in the year 2012 and on projections towards 2020. S2Biom estimates a total EU28 agricultural pruning technical potential of 14,107 to $12,252 \mathrm{ktDM} \cdot \mathrm{yr}^{-1}$ by 2012 and 2020. The data is quite in line with the results of the present work of $12,518 \mathrm{ktDM} \cdot \mathrm{yr}^{-1}$ (Table 6).

Additionally to harvesting losses and maximum operational slopes, other technical factors could have been implemented to reduce further the technical potential. Road access or remoteness are factors usually utilised in territorial analysis and in the performance of assessments of biomass feasibility-for example in forestry biomass assessments to reflect the capacity to access the forest stands. The implementation of this factor has a special interest in assessments orientated to explore the biomass supply to biomass plants or in a specific region, and has limited value when performing large-scale biomass assessments.

\subsection{Pruning Economic Potentials}

According to the results the technical potential could be fully exploitable to be utilised in areas where the driving force leading to the utilisation of pruning wood is not economic but derived from strict environmental measures or a highly aware society. This result represents several current existing value chains where the reasons for moving farmers and other value actors to withdraw the prunings from the fields are as follows [23,46]: to reduce the risk of forest fires (like the Council of Serra, in Spain); to avoid random disposal or burning in open fires under the pressure of social interest (like in Nuertingen and Esslingen-Regierungsbezirk Stuttgart, Germany); under the conviction of good practice even resulting in a non-economic balance (like the case of Xavier Muller Domain winery in Alsace, France); or to avoid risk of diseases propagation (SCEA Vignobles Jean-Marie Carrille Chateau Poupille in Aquitaine, France). In all cases there is a driving force that makes possible the mobilisation of pruning wood under a non-market orientated and economically driven model. These real cases exemplify the waste scenario, where the technical potential is not the object of economic restrictions and, therefore, mobilising all collectable biomass is feasible (Table 7). 
Table 7. Summary of total agricultural pruning biomass potential: theoretical, technical, economic and implementation (mass and energy units).

\begin{tabular}{|c|c|c|c|c|c|c|c|c|c|c|c|c|c|}
\hline & \multirow{2}{*}{$\begin{array}{l}\text { Country } \\
\text { (NUTs0) }\end{array}$} & \multicolumn{2}{|c|}{ Theoretical Technical } & \multicolumn{5}{|c|}{ Economic Potential (tDM·yr $\left.{ }^{-1}\right)$} & \multicolumn{5}{|c|}{ Implementation Potential (tDM-yr $\left.{ }^{-1}\right)$} \\
\hline & & Bio $_{T H}$ & $\mathrm{Bio}_{\mathrm{T}}$ & Bio $_{E_{-} W A S T E}$ & Bio $_{E \_S E L F}$ & Bio $_{E_{-} C O M-S}$ & Bio $_{E_{-} C O M-M}$ & Bio $_{E_{-} C O M-L}$ & Bio $_{I \_W A S T E}$ & Bio $_{I \_S E L F}$ & Bio $_{I}$ COM-S & $B i O_{I}$ СOM-M & $B i o_{I}$ СOM-L \\
\hline AT & Austria & 76,509 & 68,144 & 68,144 & 64,074 & 41,315 & 11,334 & 10,276 & 59,827 & 55,982 & 36,027 & 9793 & 8892 \\
\hline BE & Belgium & 34,899 & 31,758 & 31,758 & 31,518 & 24,620 & 24,814 & 24,778 & 30,951 & 30,714 & 24,035 & 24,226 & 24,198 \\
\hline BG & Bulgaria & 144,825 & 129,902 & 129,902 & 99,033 & 18,141 & 3416 & 76 & 118,967 & 89,791 & 16,766 & 3161 & 70 \\
\hline $\mathrm{CY}$ & Cyprus & 49,941 & 45,465 & 45,465 & 23,542 & 15,188 & 8290 & 10,049 & 37,700 & 19,593 & 12,641 & 6899 & 8363 \\
\hline CZ & Czech & 51,365 & 46,291 & 46,291 & 44,995 & 7281 & 0 & 0 & 35,183 & 33,951 & 5617 & 0 & 0 \\
\hline $\mathrm{DE}$ & Germany & 213,391 & 191,119 & 191,119 & 181,479 & 120,393 & 89,322 & 80,317 & 173,246 & 156,327 & 104,541 & 78,340 & 70,864 \\
\hline DK & Denmark & 3266 & 2972 & 2972 & 2943 & 620 & 0 & 0 & 2420 & 2390 & 496 & 0 & 0 \\
\hline $\mathrm{EE}$ & Estonia & 1800 & 1638 & 1638 & 1570 & 0 & 0 & 0 & 13 & 0 & 0 & 0 & 0 \\
\hline EL & Greece & 1316,240 & $1,240,224$ & $1,240,224$ & 935,652 & 635,495 & 635,495 & 635,495 & 891,564 & 664,841 & 457,714 & 457,714 & 457,714 \\
\hline ES & Spain & $5,043,203$ & $4,664,890$ & $4,664,890$ & $4,414,851$ & $3,637,219$ & $3,103,116$ & $3,445,630$ & $4,208,706$ & $3,971,052$ & $3,273,611$ & $2,801,501$ & $3,098,085$ \\
\hline FI & Finland & 1,110 & 831 & 831 & 800 & 482 & 125 & 63 & 561 & 539 & 325 & 84 & 42 \\
\hline FR & France & $1,287,624$ & $1,143,617$ & $1,143,617$ & $1,116,790$ & 949,882 & 793,342 & 826,914 & 990,285 & 965,615 & 819,114 & 682,173 & 710,082 \\
\hline HR & Croatia & 117,802 & 104,863 & 104,863 & 71,653 & 50,195 & 11,276 & 0 & 88,744 & 59,705 & 42,089 & 9489 & 0 \\
\hline HU & Hungary & 257,019 & 231,929 & 231,929 & 190,364 & 109,322 & 56,795 & 71,319 & 218,357 & 177,354 & 102,569 & 53,535 & 67,312 \\
\hline IE & Ireland & 945 & 860 & 860 & 860 & 584 & 358 & 483 & 851 & 851 & 578 & 355 & 478 \\
\hline IT & Italy & $3,133,348$ & $2,849,044$ & $2,849,044$ & $2,286,817$ & $1,993,000$ & $1,758,410$ & $1,877,796$ & $2,229,271$ & $1,716,895$ & $1,496,003$ & $1,319,180$ & $1,406,930$ \\
\hline LT & Lithuania & 20,695 & 18,832 & 18,832 & 17,180 & 9963 & 0 & 0 & 10,683 & 9125 & 5292 & 0 & 0 \\
\hline LU & Luxembourg & 1545 & 1366 & 1366 & 1273 & 0 & 0 & 0 & 1197 & 1114 & 0 & 0 & 0 \\
\hline LV & Latvia & 9679 & 8808 & 8808 & 8753 & 2420 & 0 & 0 & 7588 & 7535 & 2084 & 0 & 0 \\
\hline MT & Malta & 2499 & 2252 & 2252 & 1255 & 0 & 0 & 0 & 1983 & 1088 & 0 & 0 & 0 \\
\hline NL & Netherlands & 30,884 & 28,075 & 28,075 & 27,693 & 16,369 & 1867 & 0 & 27,372 & 26,994 & 16,007 & 1826 & 0 \\
\hline PL & Poland & 582,330 & 529,436 & 529,436 & 498,897 & 456,115 & 356,659 & 327,389 & 419,411 & 391,400 & 362,496 & 313,112 & 290,440 \\
\hline PT & Portugal & 682,739 & 625,484 & 625,484 & 556,357 & 456,355 & 370,324 & 442,785 & 589,551 & 522,591 & 428,422 & 347,399 & 415,369 \\
\hline RO & Romania & 507,985 & 457,032 & 457,032 & 315,265 & 118,409 & 59,276 & 70,904 & 433,314 & 298,634 & 112,425 & 56,312 & 67,359 \\
\hline SE & Sweden & 2844 & 2582 & 2582 & 2568 & 1163 & 0 & 0 & 2353 & 2339 & 1100 & 0 & 0 \\
\hline SI & Slovenia & 38,888 & 34,678 & 34,678 & 29,138 & 14,732 & 5799 & 4591 & 29,818 & 24,916 & 12,558 & 4893 & 3821 \\
\hline SK & Slovakia & 27,035 & 24,248 & 24,248 & 23,922 & 2108 & 0 & 0 & 20,681 & 20,381 & 1921 & 0 & 0 \\
\hline UK & United Kingdom & 35,931 & 32,606 & 32,606 & 32,508 & 18,438 & 14,610 & 14,610 & 30,532 & 30,436 & 17,263 & 13,833 & 13,833 \\
\hline \multirow{2}{*}{ EU28 } & Mass (tDM·yr $\left.{ }^{-1}\right)$ & $13,676,341$ & $12,518,946$ & $12,518,946$ & $10,981,752$ & $8,699,810$ & $7,304,629$ & $7,843,476$ & $10,661,130$ & $9,282,155$ & $7,351,694$ & $6,183,825$ & $6,643,854$ \\
\hline & Energy $\left(\mathrm{PJ} \cdot \mathrm{yr}^{-1}\right)$ * & 227.2 & 207.9 & 207.9 & 182.4 & 144.5 & 121.3 & 130.2 & 177.1 & 154.2 & 122.1 & 102.7 & 110.3 \\
\hline
\end{tabular}

$\left(^{*}\right)$ Energy calculated as the energy released in combustion of the biomass with $20 \%$ moisture. 
When considering the scenario of self-consumption (Table 7), and a minimum farm size of 2 hectares, some countries reveal losses larger than 20\% like Bulgaria, Cyprus, Croatia, Greece, Malta or Romania (CR explicit data in Table S1). Such a situation reveals a relevant part of the land on olive, fruit and vineyards is atomised, probably only exploitable for firewood, but not for modern uses of the bioeconomy. Also it reveals the establishment of value chains, even for waste-scoped initiatives, may require multiple mobilisation options, some of them tailored for very small tenants.

The economic cases of commercially driven value chains at small (S), medium (M) and large (L) scales-as defined in Section 2.4 and Table 3-lead to further substantial reductions in respect of the technical potentials (Table 7). As observed in $\left({ }^{*}\right)$, the energy was calculated as the energy released in combustion of the biomass with $20 \%$ moisture.

The overall reduction for Europe is relevant: $31 \%$ for COM-S, $42 \%$ for COM-M and $37 \%$ for COM-L. By country, the potential of Spain and France is reduced to less than 25\% (respect technical potential). Portugal, Greece, Poland and Italy have reductions under 50\%. Rest of countries usually cause strong reductions under the three proposed alternatives of the economic scenarios. This result indicates that there is a relevant part of the technical potential in Europe mostly appropriate to be utilised for self-consumption or to be mobilised under the pressure of environmental regulations $o$ social demands. There is however, especially in the aforementioned countries, a relevant part of the potential that can be mobilised as demanded by consumers. In order to provide further insight, Table 8 identifies the best exploitation system. As observed, pruning utilisation under commercial basis is principally exploitable under small-scale initiatives. This conclusion reveals the best method to release the economic potential is the promotion of local value chains for the exploitation of pruning (case COM-S). At NUTs2 and NUTs 3 it is also the alternative prevailing as most suitable is the exploitation in local value chains (see Supplementary Materials Tables S2 and S3, respectively). Notwithstanding the high suitability of small-scale value chains, there are some regions where, for example, a large scale is slightly better. The gap between the best economic potential and the technical (or waste-driven) potential is also incorporated in Table 8. The figure of the gap reflects the amount of the technical potential that should be mobilised under self-consumption or under waste management schemes. A visual presentation of the most suitable economic model is depicted in Figure 2 (map on the right side) by NUTs2. The disaggregation in smaller geographical units allows us to better observe the tendency, identify zones where pruning potential can be larger, and to see the share of the potential that can be exploitable for contributing to small-, medium- and large-scale market-driven applications. Every Nuts2 unit marked with the purple spot indicates that to some extent, new market driven value chains can be promoted.

Table 8. Best economic exploitation system for pruning utilisation on a commercial basis.

\begin{tabular}{|c|c|c|c|c|c|c|c|c|c|}
\hline & \multirow{2}{*}{$\begin{array}{l}\text { Country } \\
\text { (NUTs0) }\end{array}$} & \multirow{2}{*}{$\begin{array}{c}\text { Reference } \\
\text { Bio }_{T} \text { or } \\
\text { Bio }_{E_{-} W A S T E}\end{array}$} & \multicolumn{3}{|c|}{$\mathrm{CR}_{\mathrm{E} \_\mathrm{COM}}$} & \multicolumn{2}{|c|}{ Best Economic Case } & \multicolumn{2}{|c|}{ Gap Respect BioT } \\
\hline & & & $S$ & $\mathbf{M}$ & $\mathbf{L}$ & Case & $\begin{array}{c}\text { Potential } \\
\left(\mathrm{tDM} \cdot \mathrm{yr}^{-1}\right)\end{array}$ & $\begin{array}{c}\text { Absolute } \\
\left(\mathrm{tDM} \cdot \mathrm{yr}^{-1}\right)\end{array}$ & $\begin{array}{c}\text { Relative } \\
(\%)\end{array}$ \\
\hline $\mathrm{AT}$ & Austria & 68,144 & 39.4 & 83.4 & 84.9 & $\mathrm{~S}$ & 41,315 & 26,829 & 39.4 \\
\hline BE & Belgium & 31,758 & 22.5 & 21.9 & 22.0 & $\mathrm{M}$ & 24,814 & 6944 & 21.9 \\
\hline BG & Bulgaria & 129,902 & 86.0 & 97.4 & 99.9 & $S$ & 18,141 & 111,761 & 86.0 \\
\hline CY & Cyprus & 45,465 & 66.6 & 81.8 & 77.9 & S & 15,188 & 30,277 & 66.6 \\
\hline $\mathrm{CZ}$ & Czech & 46,291 & 84.3 & 100.0 & 100.0 & S & 7281 & 39,010 & 84.3 \\
\hline DE & Germany & 191,119 & 37.0 & 53.3 & 58.0 & $S$ & 120,393 & 70,726 & 37.0 \\
\hline DK & Denmark & 2972 & 79.2 & 100.0 & 100.0 & S & 620 & 2353 & 79.2 \\
\hline $\mathrm{EE}$ & Estonia & 1638 & 100.0 & 100.0 & 100.0 & - & 0 & 1638 & 100.0 \\
\hline EL & Greece & $1,240,224$ & 48.8 & 48.8 & 48.8 & $S \& M \& L$ & 635,495 & 604,729 & 48.8 \\
\hline ES & Spain & $4,664,890$ & 22.0 & 33.5 & 26.1 & S & $3,637,219$ & $1,027,671$ & 22.0 \\
\hline FI & Finland & 831 & 42.0 & 85.0 & 92.4 & S & 482 & 349 & 42.0 \\
\hline FR & France & $1,143,617$ & 16.9 & 30.6 & 27.7 & S & 949,882 & 193,735 & 16.9 \\
\hline HR & Croatia & 104,863 & 52.1 & 89.2 & 100.0 & $S$ & 50,195 & 54,669 & 52.1 \\
\hline HU & Hungary & 231,929 & 52.9 & 75.5 & 69.2 & $S$ & 109,322 & 122,607 & 52.9 \\
\hline IE & Ireland & 860 & 32.1 & 58.3 & 43.8 & $S$ & 584 & 276 & 32.1 \\
\hline IT & Italy & $2,849,044$ & 30.0 & 38.3 & 34.1 & $S$ & $1,993,000$ & 856,043 & 30.0 \\
\hline
\end{tabular}


Table 8. Cont.

\begin{tabular}{|c|c|c|c|c|c|c|c|c|c|}
\hline & \multirow{2}{*}{$\begin{array}{l}\text { Country } \\
\text { (NUTs0) }\end{array}$} & \multirow{2}{*}{$\begin{array}{c}\text { Reference } \\
\text { Bio }_{T} \text { or } \\
B^{\prime} o_{E_{-} W A S T E}\end{array}$} & \multicolumn{3}{|c|}{$\mathrm{CR}_{\mathrm{E} \_\mathrm{COM}}$} & \multicolumn{2}{|c|}{ Best Economic Case } & \multicolumn{2}{|c|}{ Gap Respect $\mathrm{Bio}_{\mathrm{T}}$} \\
\hline & & & $S$ & $\mathbf{M}$ & $\mathbf{L}$ & Case & $\begin{array}{c}\text { Potential } \\
\left(\mathrm{tDM} \cdot \mathrm{yr}^{-1}\right)\end{array}$ & $\begin{array}{c}\text { Absolute } \\
\left(\mathrm{tDM} \cdot \mathrm{yr}^{-1}\right)\end{array}$ & $\begin{array}{c}\text { Relative } \\
(\%)\end{array}$ \\
\hline LT & Lithuania & 18,832 & 47.1 & 100.0 & 100.0 & $\mathrm{~S}$ & 9963 & 8869 & 47.1 \\
\hline LU & Luxembourg & 1366 & 100.0 & 100.0 & 100.0 & - & 0 & 1366 & 100.0 \\
\hline LV & Latvia & 8808 & 72.5 & 100.0 & 100.0 & S & 2420 & 6388 & 72.5 \\
\hline MT & Malta & 2252 & 100.0 & 100.0 & 100.0 & - & 0 & 2252 & 100.0 \\
\hline NL & Netherlands & 28,075 & 41.7 & 93.3 & 100.0 & S & 16,369 & 11,706 & 41.7 \\
\hline PL & Poland & 529,436 & 13.8 & 32.6 & 38.2 & $S$ & 456,115 & 73,321 & 13.8 \\
\hline PT & Portugal & 625,484 & 27.0 & 40.8 & 29.2 & $S$ & 456,355 & 169,130 & 27.0 \\
\hline RO & Romania & 457,032 & 74.1 & 87.0 & 84.5 & S & 118,409 & 338,623 & 74.1 \\
\hline SE & Sweden & 2582 & 55.0 & 100.0 & 100.0 & S & 1163 & 1419 & 55.0 \\
\hline SI & Slovenia & 34,678 & 57.5 & 83.3 & 86.8 & $\mathrm{~S}$ & 14,732 & 19,946 & 57.5 \\
\hline SK & Slovakia & 24,248 & 91.3 & 100.0 & 100.0 & S & 2108 & 22,140 & 91.3 \\
\hline UK & $\begin{array}{l}\text { United } \\
\text { Kingdom }\end{array}$ & 32,606 & 43.5 & 55.2 & 55.2 & $M \& L$ & 18,438 & 14,167 & 43.5 \\
\hline & EU28 & $12,518,946$ & 30.5 & 41.7 & 37.3 & $\mathrm{~S}$ & $8,699,810$ & $3,819,136$ & 30.5 \\
\hline
\end{tabular}

S: Small; M: Medium; L: Large. Cells in shadow denote the best system to implement the economic potential.

\subsection{Pruning Implementation Potentials}

The implementation potentials (Table 7) derive from the economic potentials and include a reduction factor considering competitive uses and the potential prioritisation of in-farm uses of the pruning in organic farming. The results of the assessment show that the potentials are slightly reduced in respect of the economical potentials, only about $14.8 \%$ in the overall of the EU28 (see $\left(^{*}\right)$ in Table 7 , where the energy was calculated as the energy released in combustion of the biomass with $20 \%$ moisture.

In general the competitiveness coefficient of reduction is low, as the competitive uses are quite limited, except in some specific geographical areas. Organic farming further contributes to a small reduction, but, as observed in most countries the restrictions for implementation are rather limited. According to Eurostat statistical data, some countries declare a rather large share of the and under organic farming, especially countries with small areas dedicated to olive, grape and fruit production (like Estonia or Luxembourg).

The potentials obtained cannot be compared with those obtained in S2Biom as they incorporate other assumptions like constraints of the sustainable potentials, leading to strong reductions, and figures under $5 \mathrm{Mt} \cdot \mathrm{yr}^{-1}$ of dry matter are considered as implementable and sustainable.

\subsection{Pruning Sustainable Potentials}

Agricultural pruning biomass technical, economic and implementation potentials are a realistic base for energy planning. At large scale, they provide figures adequate for sizing the relevance of a biomass resource, and indications of the modes of exploitation most suitable in each regional context. However a sustainable utilisation of renewable energies requires the consideration of environmental and sustainability issues. Environmental and sustainability regulations have to be considered to understand the share of the implementation potential than can be put in practice whilst ensuring sustainable use. The values proposed in Section 2.6 for the coefficients of reduction are discussed in the next paragraphs.

\subsubsection{Effect of Local Impacts, Special Protected Areas and Origin of the Sustainable Potentials}

According to the values presented in the section of methodology, there are three criteria on sustainability that are not leading in principle to reductions in the pruning biomass sustainable potential: local impacts of pruning utilisation $\left(C R_{S_{-} E I A}=0\right)$, pruning wood in fields grown in Special Protected Areas $\left(C R_{S \_S P A}=0\right)$ and origin and induction of land-use changes $\left(C R_{S_{-} O R I G I N}=0\right)$. 
These values are expected to be adequate for a majority of the EU28 contexts, although locally some incompatibilities could occur. It should be foreseen that the local impacts of activities are a potential risk for causing environmental impacts. As described for agricultural pruning in Section 2.6.1, the observation of multiple works did not reveal any evidence of incompatibility. Notwithstanding this general rule, the assessments on a smaller scale should report the expected operations to be put in practice to determine any potential risk. Special Protected Areas and incompatibility of pruning use may play as well a role locally. It is recommended to apply this potential restriction for research assessments to a smaller scale, although in the aggregated potentials for the EU28 the potential shall be considered to be affected only very marginally. In terms of the origin and the potential induction of direct or indirect land use change (LUC), Section 2.6.5 proposes the pruning to be fully compatible, as an increased interest in the use of an agricultural residue may have an influence in the competitiveness and market prices, but will not trigger any land-use change, any extension of the permanent crops land cultivated, or any import.

\subsubsection{Sustainable Potentials as Affected by the Request for Greenhouse Gas (GHG) Emissions Saving}

The EuroPruning project demonstrated the low GHG emissions derived from pruning utilisation [51]: from 8 to $12 \mathrm{~g} \mathrm{CO}_{2} \mathrm{eq} \cdot \mathrm{MJ}^{-1}$ for five crops-olive, vineyards, apple, peach and almond. The renewable energy Directive (EU) 2018/2001 does not provide any specific default value of emissions for pruning wood. There is, however, a generic group for agricultural residues of low bulk density (lower than $0.2 \mathrm{t} \cdot \mathrm{m}^{-3}$ ) or high bulk density (lower than $0.2 \mathrm{t} \cdot \mathrm{m}^{-3}$ ). EuroPruning demo results showed bulk density values in an interval above and under $0.2 \mathrm{t} \cdot \mathrm{m}^{-3}$, being hog fuel and woodchips usually above the threshold, and bales under it. The S2Biom project compiled biomass characteristics from multiple literature resources and provided typical ranges of bulk densities for pruning processed as hog-fuel above $0.2 \mathrm{t} \cdot \mathrm{m}^{-3}$ and under this threshold for pruning bales. The present work considers the most restrictive case of bulk densities of processed agricultural pruning under $0.2 \mathrm{t} \cdot \mathrm{m}^{-3}$. The GHG emissions factors of Directive (EU) 2018/2001 for this type of feedstock range from 3.7 to $4.5 \mathrm{~g} \mathrm{CO}_{2} \mathrm{eq} \cdot \mathrm{MJ}^{-1}$ [3] — values selected correspond to transport distances of less than $500 \mathrm{~km}$, following the economic scenarios discussed in the section of economic potentials (Section 2.4). These values are much lower than those found in EuroPruning. The difference shall stem from the method, since EuroPruning included an emission factor associated with the fertiliser needed to be added to soil to compensate for the withdrawal of nutrients when pruning is collected. This factor ranges 3 to $5 \mathrm{~g} \mathrm{CO}_{2} \mathrm{eq} \cdot \mathrm{MJ}^{-1}$ [51], which may explain partially the deviations. Additionally, pruning harvest and logistics are less optimised and therefore more intensive in energy than those for straw.

Considering the values obtained by EuroPruning the savings would still stay in the range of $83 \%$ to $86 \%$ for heat production and $74 \%$ to $78 \%$ for electricity production. The reductions requested by Directive (EU) 2018/2001 are 93\% and 95\% for heat production, and between $90 \%$ and $92 \%$ for electricity generation. As observed, agricultural pruning can be considered in principle sustainable and, thus, to be considered that GHG emissions do not constraint the implementation potentials. It should be emphasized that the assessment of GHG reductions should incorporate the emissions associated with the logistic schemes and the value chain size and scale. For a EU28 assessment, this should differentiate the specificities of each region. Following such an approach the value of the coefficients of reduction (CR) could be obtained more precisely in each geographical unit.

\subsubsection{Sustainable Potentials as Affected by the Request on GHG Emissions Saving}

As proposed in Section 2.6.3, the compatibility of the agricultural pruning removal with soil sustainability can be performed on the base of existing regulations. Even though researchers have not found any regulation on pruning residues (on the compulsory utilisation as organic input to the soil), some assessments for straw [10] have followed this approach. The difficulty stems from the absence of coherent or coordinated regulations at the EU scale. These regulations are usually formulated at national or sub-national governance levels. Scarlat and co-workers [10] obtained some reasonable and 
generic coefficients of reduction for straw potentials applicable to Europe following this approach. On the basis of the analysis, they set sustainable removal rates of $40 \%$ for cereals and $50 \%$ for other annual crops.

An alternative method is the review of specialised research results. Several reports denote that overall, the energy use of prunings is not opposed to sustainable soil management and long-term soil fertility $[55,56]$. Local factors like erosion control or agronomic strategies for organic matter preservation or increase are determinant to alternative $C$ inputs by other plant materials, e.g., grass covers must be taken into consideration to counteract potential problems. Prunings can be removed, if other carbon sources such as a grass cover are present and nutrient exports are compensated for e.g., by fertilization. EuroPruning conclusions [55]—which are based on a follow-up of soil parcels in three European climatic zones-postulate that pruning wood should be preserved and not mobilised when the conditions cannot ensure a green grass cover larger than $80 \%$ in weak soils, soils exposed to erosion, soils of easy compaction, or soils tending to water-logging and creation of anoxic conditions. The same recommendation applies for poor soils and soils where grass cover cannot reach $3 \mathrm{tDM} \cdot \mathrm{ha}^{-1} \cdot \mathrm{yr}^{-1}$. This result is adequate for providing guidance to farmers or technicians when evaluating the best fate of the pruning wood field by field. However these rules cannot be applied at the EU28 scale as there is not sufficiently accurate data on which applying the rules.

The uP_running project proposes a simplified Red-Yellow-Green method [56] based on soil texture, SOM content, soil slope and climatic conditions (aridity index). The method was designed to support farmers or advising/extension services to understand the implications that sustained pruning use shall have in the plantation soil. The method could be implemented spatially based on existing soil, slope and climatic dataset in the form of grids for Europe. For cases classified as "green", there is no restriction in the use of the pruning wood. For cases classified as "yellow" it is advised a series of management practices to ensure good maintenance of the SOM. In cases detected to be "red", a series of practices are indicated and it recommends the use of the pruning as organic input to the soil as the default practice to be adopted. The method requires as part of the input data the current soil cover management and, therefore, it is not easily applicable at large scales.

A step forward is the modelling of the carbon balances in large scale assessments basing on existing soil and climate databases and on the modelling od the soil dynamics. The EuroPruning [51] and S2Biom [17] projects applied the RothC model (Rothamsted Carbon Model) to calculate the soil carbon dynamics of five crop groups: (1) Apples, pears and peaches, (2) Citrus fruits, (3) Other fruits, (4) Olives and (5) Grapes. Crop groups were arranged accordingly the CAPRI (Common Agricultural Policy Regionalised Impact) data and crop typology. The RothC model calculates the turnover of organic carbon in non-waterlogged soils based on monthly climatic data, and the effects of soil type, soil moisture content and plant cover. The carbon inputs considered were pruning wood, litter fall, wasted fruit, crop rooting system, manure and grass. The model provided as a result the potential amount of prunings that can be removed without decreasing the SOC stock. The model revealed that the rooting dynamics, the grass cover, and the pruning wood were the most relevant sources for carbon fixation into the agricultural soil. The model outputs suggested relevant restrictions to the use of prunings, especially in Mediterranean areas. The results implied in terms of total cut-down of the implementation potentials reduction percentages from $50 \%$ to $75 \%$. This figure is much more restrictive than the values suggested by Scarlat and co-workers [10] (as mentioned above) or by Montforti and co-workers [24] (who applied modelling to simulate carbon, nitrogen, phosphorus and sulphur dynamics in annual crop cultivated soils) and obtained as aggregated result a need to let on soils about $40 \%$ of the agricultural residues of annual crops.

The EuroPruning [51] and S2Biom [17] reports argue the RothC model inputs need to be further researched, as a low grass cover yield in the input data of the RothC model was evident, and due to the limited number of observation of the LUCAS (Land Use/Cover Area frame statistical Survey Soil) inventory [57] reporting permanent crops surveyed parcels. The report concludes that the results do not contradict the conclusions derived from the EuroPruning soil parcels follow-up [55]. In agreement 
with the uP_running vision and assessment method on pruning use compatibility with soil sustainable management [56], it is pointed out that preserving soil organic matter is the result of crop management including: grass cover, method of mowing/removal, addition of manure, management of the cover (use of superficial tillage), among others. In case there is a risk of organic matter decline, several actions are recommended [56], which is not necessarily limiting the use of the pruning wood, except in severe cases.

\subsubsection{Sustainable Potentials}

Based on the coefficients of reduction the sustainable potentials are principally affected by the compatibility of the pruning utilisation with the preservation of SOC in the agricultural soils. According to the aggregated results, the reductions could range from $50 \%$ to $75 \%$ These figures should be considered as an indicator that, in principle, soil sustainability is a principal issue in the sustainable utilisation of the agricultural pruning. Assuming 50\% of cut-down of the implementation potential, the final aggregated figure of the potentials could range approximately from 5 to $3.3 \mathrm{MtDM} \cdot \mathrm{yr}^{-1}$. This figure represents a total descent of 65 to $75 \%$ of the total potential. These figures should be taken with caution. For energy planning it is, in principle, recommended the utilisation of the implementation potentials, and consider the soil sustainability as an element to be traced and regulated.

\subsection{Relevance of Pruning Potential in the EU28 Energy Context}

The total implementable potential of agricultural pruning is estimated to sum up to 9.2 and $7.3 \mathrm{MtDM} \cdot \mathrm{yr}^{-1}$ considering the resources exploitable under self-consumption $\left(C R_{I \_S E L F}\right)$ and commercial scales $\left(C R_{I_{-} C O M-S}\right)$, respectively. In terms of energy (Tables 6 and 7$)$ the total thermal energy that this biomass can release when utilised in the boiler amounts to $154.2 \mathrm{PJ} \cdot \mathrm{yr}^{-1}$ (for $C R_{I \_S E L F}$ ) and $122.1 \mathrm{PJ} \cdot \mathrm{yr}^{-1}$ (for $C R_{I_{-} C O M-S}$ ). These values constitute a $2.2-2.8 \%$ share in biomass resources (in relation to 2018) and a $2.0-2.5 \%$ share in the projection of the biomass use in 2030. It shows that this is not a major resource, but can provide a relevant contribution at a local scale. Nevertheless, it can save ca. 7.0 Mt of bituminous coal or serve as a heating source for ca. 2.1 million households.

\section{Conclusions}

The estimation of the biomass potential coming from yearly pruning of permanent crops is complex. The study published a transparent biomass assessment for Europe with all steps and coefficients, available at NUTs2 and NUTs3, which should be very helpful for policy makers, companies, sectorial organisations and for local authorities engaged in energy planning.

This study highlights that the pruning potential depends on many factors, where the technical constraints, economic aspects related to the value chain adopted and other constraints (like competitiveness) may lead to almost $50 \%$ reduction of theoretical potential determined in this study amounting to 13.7 million tonnes (DM) per year or $252.0 \mathrm{PJ} \cdot \mathrm{yr}^{-1}$. Despite this reduction in cumulative EU28 pruning potential, the technical potential $\left(12.5 \mathrm{MtDM} \cdot \mathrm{yr}^{-1}, 230.6 \mathrm{PJ} \cdot \mathrm{yr}^{-1}\right)$ may be unblocked with two additional strategies: firstly self-consumption promotion; secondly the widespread of compulsory appropriate handling of the pruning residues (as part of the waste management programs in a region). As a result, the implementation potential varies from 6.6 to $10.6 \mathrm{MtDM} \cdot \mathrm{yr}^{-1}$ of pruning residues (122.3-196.6 PJ. $\mathrm{yr}^{-1}$ ). Furthermore, beyond the EU28 or country-aggregated figures, the regional results indicate that the local possibilities of pruned biomass acquisition for a given permanent crop are significant and may play an important role as an energy source (mainly heat) for domestic and middle-size boilers.

Further work should address the issue of sustainable potential assessment for agricultural pruning biomass which is influenced by local conditions, carbon balance and soil properties. Finally, there is also a subject related to the implementation of additional biomass resources available in permanent crops, namely wooden biomass from total plantation/orchard removal. The present work proposes 
continuity in the assessment of this feedstock, which produces large amounts of biomass albeit not annually but at the end of the plantation lifetime.

Supplementary Materials: The following are available online at http:/www.mdpi.com/1996-1073/12/8/1513/s1, Figure S1: Regional theoretical pruning potential by NUTs2 level in EU28. Figure S2: Regional theoretical pruning potential by NUTs3 level in EU28. Table S1: summary of CRs and biomass potentials for EU28 by NUTs0. Table S2: summary of CRs and biomass potentials for EU28 by NUTs2. Table S3: summary of CRs and biomass potentials for EU28 by NUTs3.

Author Contributions: A.D. and D.G.-G. conceived and designed the research, performed the research; analyzed the data and contributed materials/analysis tools. A.D. and D.G.-G. scoped and assessed the theoretical potential. A.D. had a leading role in technical and implementation potential. D.G.-G led the economic potentials. D.G.-G performed the GIS operations and scoped the discussion on sustainability. A.D. and D.G.-G. wrote the paper.

Funding: This research was funded by the European Commission's Seventh Framework Programme under the grant contract FP7-KBBE-312078, entitled EuroPruning Project ("Development and implementation of a new and non-existent logistics chain for biomass from pruning"). The APC was funded by Wroclaw University of Environmental and Life Science (pro-development sources D210/0021/18).

Acknowledgments: The authors would also like to express their sincere gratitude to all collaborators in advising to scope part of the coefficients applied in the present work.

Conflicts of Interest: The funders had no role in the design of the study; in the collection, analyses, or interpretation of data; in the writing of the manuscript; or in the decision to publish the results.

$\begin{array}{ll}\text { Abbreviations } \\ \text { Bio } & \text { biomass } \\ \text { CR } & \text { Coefficients of Reduction } \\ \text { DEM } & \text { Digital Elevation Model } \\ \text { DM } & \text { Dry Mass } \\ \text { E } & \text { Economic } \\ \text { EIA } & \text { Environmental Impact Assessments } \\ \text { EU28 } & \text { 28 member states belonging to the European Union } \\ \text { GAEC } & \text { Good Agricultural and Environmental Conditions } \\ \text { GHG } & \text { greenhouse gas } \\ \text { GIS } & \text { Geographical Information System } \\ \text { I } & \text { Implementation } \\ \text { IRR } & \text { irrigated } \\ \text { LHV } & \text { lower heating value } \\ \text { LUC } & \text { Land-Use Change } \\ \text { LUCAS } & \text { Land-Use/Cover Area frame statistical Survey Soil } \\ \text { NREAP } & \text { European National Renewable Action Plan } \\ \text { NUTs } & \text { Nomenclature of territorial units for statistics } \\ \text { OF } & \text { organic farming } \\ \text { RFED } & \text { rainfed } \\ \text { RPR } & \text { residue to product ratio } \\ \text { RSR } & \text { Residue to Surface Ratio } \\ \text { S } & \text { Sustainable } \\ \text { SOC } & \text { soil organic carbon } \\ \text { SOM } & \text { soil organic matter } \\ \text { SPA } & \text { Special Protected Areas } \\ \text { SRTM } & \text { Shuttle Radar Topographic Mission } \\ \text { TH } & \text { Theoretical } \\ T & \text { Technical } \\ \text { W } & \end{array}$




\section{References}

1. European Commission. A Roadmap for Moving to a Competitive Low Carbon Economy in 2050; European Commission: Brussels, Belgium, 2011.

2. European Comission. Commission Communication on a Policy Framework for Climate and Energy from 2020 to 2030_COM(2014) 0015; European Commission: Brussels, Belgium, 2014.

3. European Parliament Directive (EU) 2018/2001 of the European Parliament and of the Council of 11 December 2018 on the promotion of the use of energy from renewable sources (recast). Off. J. Eur. Union 2018, 2018, 128.

4. Bioenergy Europe. Bioenergy Europe, Statistical Report, 2018 Edition ed; Bioenergy Europe: Brussels, Belgium, 2019.

5. Sustainable and Optimal Use of Biomass for Energy in the EU Beyond 2020. Final Report. May 2017. Available online: https:/ec.europa.eu/energy/sites/ener/files/documents/biosustain_report_final.pdf (accessed on 18 January 2019).

6. Bentsen, N.S.; Felby, C. Biomass for energy in the European Union-A review of bioenergy resource assessments. Biotechnol. Biofuels 2012, 5, 25. [CrossRef] [PubMed]

7. Panoutsou, C.; Eleftheriadis, J.; Nikolaou, A. Biomass supply in EU27 from 2010 to 2030. Energy Policy. 2009, 37, 5675-5686. [CrossRef]

8. Monforti, F.; Bódis, K.; Scarlat, N.; Dallemand, J.-F. The possible contribution of agricultural crop residues to renewable energy targets in Europe: A spatially explicit study. Renew. Sustain. Energy Rev. 2013, 19, 666-677. [CrossRef]

9. De Wit, M.P.; Faaij, A. European biomass resource potential and costs. Biomass Bioenergy 2009, 34, 188-202. [CrossRef]

10. Scarlat, N.; Martinov, M.; Dallemand, J.-F. Assessment of the availability of agricultural crop residues in the European Union: Potential and limitations for bioenergy use. Waste Manag. 2010, 30, 1889-1897. [CrossRef]

11. Scarlat, N.; Blujdea, V.; Dallemand, J.-F. Assessment of the availability of agricultural and forest residues for bioenergy production in Romania. Biomass Bioenergy 2011, 35, 1995-2005. [CrossRef]

12. Fischer, G.; Prieler, S.; van Velthuizen, H.; Berndes, G.; Faaij, A.; Londo, M.; de Wit, M. Biofuel production potentials in Europe: Sustainable use of cultivated land and pastures, Part II: Land use scenarios. Biomass Bioenergy 2010, 34, 173-187. [CrossRef]

13. Fischer, G.; Hizsnyik, E.; Prieler, S.; Shah, M.; van Velthuizen, H. Biofuels and food Security. OFID Study Prepared by IIASA; IIASA-Intenational Institute for Applied Systems Analysis: Vienna, Austria, 2009.

14. Fischer, G.; Hizsnyik, E.; Prieler, S.; van Velthuizen, H. Assessment of Biomass Potentials for Biofuel Feedstock Production in Europe: Methodology and Results; IIASA-Intenational Institute for Applied Systems Analysis: Vienna, Austria, 2007.

15. Elbersen, B.; Startisky, I.; Hengeveld, G.; Schelhaas, M.-J.; Naeff, H.; Böttcher, H. Atlas of EU Biomass Potentials: Spatially Detailed and Quantified Overview of EU Biomass Potential Taking into Account the Main Criteria Determining Biomass Availability from Different Sources. Deliverable 3.3. Biomass Futures Project; Alterra/IIASA (IEE 08653 S12.529 241 3.3). 2012. Available online: https://ec.europa.eu/energy/intelligent/projects/sites/iee-projects/files/projects/documents/biomass_ futures_atlas_of_technical_and_economic_biomass_potential_en.pdf (accessed on 23 January 2019).

16. Bentsen, N.S.; Felby, C.; Thorsen, B.J. Agricultural residue production and potentials for energy and materials services. Prog. Energy Combust. Sci. 2014, 40, 59-73. [CrossRef]

17. Dees, M.; Höhl, M.; Datta, P.; Forsell, N.; Leduc, S.; Fitzgerald, J.; Verkerk, H.; Zudin, S.; Lindner, M.; Elbersen, B.; et al. A Spatial Data Base on Sustainable Biomass Cost-Supply of Lignocellulosic Biomass in Europe-Methods \& Data Sources; Deliverable Report D1.6-S2Biom Project; University of Freiburg: Freiburg, Germany, 2017; Available online: http://s2biom.alterra.wur.nl/doc/S2Biom_D1_6_version_19_Jan_2017.pdf (accessed on 23 January 2019).

18. García-Galindo, D.; Dyjakon, A.; Cay Villa-Ceballos, F. Building Variable Productivity Ratios for Improving Large Scale Spatially Explicit Pruning Biomass Assessments. Energies 2019, 12, 957. [CrossRef]

19. Panoutsou, C.; Bauen, A.; Elbersen, B.; Dees, M.G.; Stojadinovic, D.; Glavonjic, B.; Zheliezna, T.; Wenzelides, L.; Langeveld, H. Chapter 1-Biomass Supply Assessments in Europe: Research Context and Methodologies. In Modeling and Optimization of Biomass Supply Chains; Panoutsou, C., Ed.; Academic Press: Cambridge, MA, USA, 2017; pp. 1-24. ISBN 978-0-12-812303-4. 
20. Vis, M.W.; van den Berg, D. Harmonization of Biomass Resource Assessments. Best Practices and Methods Handbook. Deliverable Report D5.3., BEE Project (Contract FP7-213417). 2010. Available online: http://www.eu-bee.eu/_ACC/_components/ATLANTIS-DigiStore/BEE\%20Best\%20Practices\% 20and\%20methods\%20handbook8d4c.pdf?item=digistorefile;249820;837\&params=open;gallery (accessed on 5 February 2019).

21. Hirschmugl, M. Combination and Harmonization of EO and Terrestrial Methods. Deliverable Report D4.3. CEUBIOM Project (Contract FP7-213644). 2010. Available online: https://www.siea.sk/materials/files/ medzinarodne/projekty/ceubion/Report_on_harmonised_approach.pdf (accessed on 4 February 2019).

22. Dees, M.; Datta, P.; Höhl, M.; Fitzgerald, J.; Verkerk, H.; Zudin, S.; Lindner, M.; Forsell, N.; Leduc, S.; Elbersen, B.; et al. Atlas with Regional Cost Supply Biomass Potentials for EU 28, Western Balkan Countries, Moldavia, Turkey and Ukraine. Deliverable Report D1.8., S2Biom Project (FP7-608622). Available online: http: //s2biom.alterra.wur.nl/doc/S2Biom_D1_8_v1_1_FINAL_19_04_2017_CP.pdf (accessed on 4 February 2019).

23. EuroPruning. Report on Logistics Chain and Knowledge gaps of Biomass. Project Report D5.1. EuroPruning Project (FP7-312078); SLU 2016. Available online: http://www.europruning.eu/web/data/category.aspx?id= smartlogistics (accessed on 30 December 2018).

24. Monforti, F.; Lugato, E.; Motola, V.; Bodis, K.; Scarlat, N.; Dallemand, J.-F. Optimal energy use of agricultural crop residues preserving soil organic carbon stocks in Europe. Renew. Sustain. Energy Rev. 2015, 44, 519-529. [CrossRef]

25. Dyjakon, A. The Influence of Apple Orchard Management on Energy Performance and Pruned Biomass Harvesting for Energetic Applications. Energies 2019, 12, 632. [CrossRef]

26. García-Galindo, D.; Pascual, J.; Asin, J.; Garcia-Martín, A. Variability and confidence interval in the estimation of agricultural residual biomass at a municipality level in Teruel province (Spain). In Proceedings of the 15th European Biomass Conference, Berlín, Germany, 7-11 May 2007.

27. Dyjakon, A. The Influence of the Use of Windrowers in Baler Machinery on the Energy Balance during Pruned Biomass Harvesting in the Apple Orchard. Energies 2018, 11, 3236. [CrossRef]

28. EUROSTAT Farm Structure Survey. Data Provided by European Statistical Data Support (ESDS) Service by NUTs3 for the Internal Use of Data into EuroPruning; EUROSTAT Database Version 4.7/2013-07-19; European Commission: Luxembourg, 2013.

29. EUROSTAT Regional Statistics by NUTs Classification of Eurostat. Data on Regional Agriculture Statistics. "Structure of Agricultural Holdings" Dataset. Available online: http://ec.europa.eu/eurostat/web/regions/ data/database (accessed on 10 December 2018).

30. CIRCE. Results with Conclusions of Each Demonstration (by Zone and Step); Project Report D6.2. EuroPruning Project (FP7-312078); CIRCE: Zaragoza, Spain, 2016.

31. Cavalaglio, G.; Cotana, S. Recovery of vineyards pruning residues in an agro-energetic chain. In Proceedings of the 15th European Biomass conference and Exhibition; ETA Florence: Berlin, Germany, 2007.

32. Acampora, A.; Croce, S.; Assirelli, A.; Del Giudice, A.; Spinelli, R.; Suardi, A.; Pari, L. Product contamination and harvesting losses from mechanized recovery of olive tree pruning residues for energy use. Renew. Energy 2013, 53, 350-353. [CrossRef]

33. Assirelli, A.; Croce, S.; Acampora, A. Potature di olivo da energia: Le trinciacaricatrici piů adatte. L'Informatore Agrario 2012, 25, 32-36.

34. Velázquez-Martí, B.; Fernández-González, E. Analysis of the process of biomass harvesting with collecting chippers fed by pick up headers in plantations of olive trees. Biosyst. Eng. 2009, 104, 184-190. [CrossRef]

35. Spinelli, R.; Magagnotti, N.; Nati, C.; Pari, L.; Vanneste, J. Recovering Kiwifruit Pruning Residues for Biomass Production. Trans. ASABE 2012, 55, 21-28. [CrossRef]

36. Dyjakon, A.; Mudryk, K. Energetic Potential of Apple Orchards in Europe in Terms of Mechanized Harvesting of Pruning Residues. In Renewable Energy Sources: Engineering, Technology, Innovation; Springer: Cham, Switzerland, 2018; pp. 593-602. ISBN 978-3-319-72370-9.

37. Magagnotti, N.; Luigi, P.; Picchi, G. SR Technology alternatives for tapping the pruning residue resource. Bioresour. Technol. 2013, 128, 697-706. [CrossRef]

38. Den Boer, J.; Gómez, M.; Sebastián, F.; García-Galindo, D.; Dyjakon, A.; Bukowski, P.; den Boer, E.; Germer, S.; Bischoff, W.-A. No Pruning Residues: Energy Production or Mulching? Environmental Impacts of Almond Pruning Residues Use. In Proceedings of the 24th European Biomass Conference and Exhibition, Amsterdam, The Netherlands, 6-9 June 2016; pp. 1485-1489. 
39. Dyjakon, A. Harvesting and Baling of Pruned Biomass in Apple Orchards for Energy Production. Energies 2018, 11, 1680. [CrossRef]

40. Spinelli, R.; Lombardini, C.; Pari, L.; Sadauskiene, L. An alternative to field burning of pruning residues in mountain vineyards. Ecol. Eng. 2014, 70, 212-216. [CrossRef]

41. Jarvis, A.; Reuter, H.; Nelson, A.; Guevara, E. Hole-Filled Seamless SRTM Data V4; Technical Report; International Centre for Tropical Agriculture (CIAT): Montpellier, France, 2008.

42. EEA Raster Data on Land Cover for the CLC2006 Inventory-Version 17 (12/2013); European Environment Agency-EEA: Copenhagen, Denmark, 2014.

43. uP_running. uP_running Demonstration Case Studies Analysis; Deliverable Report D3.3, uP_running Project (H2020-691748); CIRCE: Zaragoza, Spain, 2019.

44. uP_running. Flagship Success Cases Update v1; Deliverable Report D6.3, uP_running Project (H2020 691748); CIRCE: Zaragoza, Spain, 2017.

45. uP_running. Flagship Success Cases Update v2; Deliverable Report D6.3, uP_running Project (H2020 691748); CIRCE: Zaragoza, Spain, 2019.

46. uP_running. Observatory Map of Biomass from Agrarian Pruning and Plantation Removal. Available online: http://www.up-running-observatory.eu/en (accessed on 15 January 2019).

47. EuroPruning. Best Practice Brochure for a Sustainable and Sound Utilization of Wood Prunings as Biomass Feedstock; Project Report D8.4, EuroPruning Project (FP7-312078); Wroclaw University of Environmental and Life Sciences (WUELS): Wroclaw, Poland, 2016.

48. Bodegas Torres Wine \& Sustainability Biomass Boiler: Pruning Residue as An Eco-Friendly Fuel. Available online: https://www.torres.es/en/blog/wine-planet/wine-sustainability (accessed on 18 January 2019).

49. CIRCE. Mapping and Analysis of the Pruning Biomass Potential in Europe; Project Report D3.1, EuroPruning Project (FP7-312078); CIRCE: Zaragoza, Spain, 2014.

50. European Commission Biomass. Available online: https://ec.europa.eu/energy/en/topics/renewable-energy/ biomass (accessed on 20 February 2019).

51. WUELS. Report on Environmental Evaluation of the Supply Chain; Project Report D8.1., EuroPruning Project (FP7-312078); WUELS: Wroclaw, Poland, 2016.

52. S2Biom. Biomass Properties. Annex to Project Report D2.4. S2Biom Project (FP7-608622). Available online: https://www.s2biom.eu/images/Publications/Annex_D2.4_S2BIOM_biomass_properties.pdf (accessed on 12 February 2019).

53. Pari, L.; Suardi, A.; Santangelo, E.; García-Galindo, D.; Scarfone, A.; Alfano, V. Current and innovative technologies for pruning harvesting: A review. Biomass Bioenergy 2017, 107, 398-410. [CrossRef]

54. Acampora, A.; Croce, S.; Barontini, M.; Assirelli, A.; Pari, L. Mechanized Recovery of Olive Tree Pruning: Harvesting Losses and Ash Product. In Proceedings of the 22st European Biomass Conference and Exhibition; ETAFLORENCE: Hamburg, Germany, 2014; pp. 70-73.

55. Bischoff, W.-A.; Germer, S.; Schleicher, S.; Kern, J. Sustainable Soil Management, Based on Field Trial Sites. Major Results, Conclusions and Recommendations; Report D7.3, EuroPruning Project (FP7-312078); CIRCE: Zaragoza, Spain, 2016.

56. Monteleone, M.; Cammerino, A.-R.; Lopriore, G.; Libutti, A. Management of Pruning Residues in a Fruit Tree Plantation: Gaining a Positive Trade-off between Soil Fertility and Bioenergy Conversion. Monograph 2, uP_running Project. Available online: https://www.up-running.eu/other-materials/ (accessed on 10 April 2019).

57. Tóth, G.; Jones, A.; Montanarella, L. (Eds.) LUCAS Topsoil Survey—Methodology, Data and Results; EUR26102EN Scientific and Technical Research Series; Publications Office: Luxembourg, 2013.

(C) 2019 by the authors. Licensee MDPI, Basel, Switzerland. This article is an open access article distributed under the terms and conditions of the Creative Commons Attribution (CC BY) license (http://creativecommons.org/licenses/by/4.0/). 